\title{
Pegs, Risk Management, and Financial Crises*
}

\author{
Parag A. Pathak ${ }^{\dagger}$ and Jean Tirole ${ }^{\ddagger}$
}

July 28,2004

\begin{abstract}
The paper builds a simple, micro-founded model of exchange rate management, speculative attacks, and exchange rate determination. The country can pick an ambitious peg in an attempt to signal a strong currency and thereby attract foreign capital or boost future re-election prospects. The peg, however, triggers speculative attacks that the country must withstand for the signal to remain credible. Maintaining the peg is costly to a country with an overvalued currency as it must sell the foreign currency at an unfavorable rate.

We show that speculative activities can exhibit strategic complementarity or substitutability. We then relate the peg's ambition and the size of the ensuing speculative attack to the market's prior beliefs about the strength of the currency, the ability of foreign speculators to short sell the currency, domestic politics, and the initial debt composition.

Finally, the model predicts that pegs and features of original sin emerge concurrently. Country hedging is endogenously incomplete as letting the residents hedge is a clear admission that the currency is overvalued by the market and makes any complementary attempt at exchange rate management futile. Similarly, we show that a peg may make domestic borrowers eager to issue short-term liabilities so as to provide foreign investors with an advantageous exit option. Furthermore, the government does not incentivize firms to lengthen the maturity structure even when it wants to because doing so would again be an open admission of a future depreciation.
\end{abstract}

Keywords: Exchange rate management, speculative attacks, hedging, financial crises.

JEL class: D82, F33, F34.

*We are grateful to Alberto Alesina, Olivier Jeanne, Henri Pagés, Ken Rogoff and to participants at the Lehman Brothers FMG-LSE Liquidity conference and a seminar at the Banque de France for helpful comments. For financial support, Pathak thanks the National Science Foundation and the Division of Research at Harvard Business School and Tirole thanks the Fondation Banque de France.

${ }^{\dagger}$ Harvard University, e-mail: ppathak@fas.harvard.edu, www: http://www.fas.harvard.edu/ ppathak

${ }_{\ddagger}^{\ddagger}$ IDEI and GREMAQ (UMR 5603 CNRS), Toulouse, CERAS (URA 2036 CNRS), Paris, and MIT, e-mail: tirole@cict.fr, www: http://idei.fr/member.php?i=3. 


\section{Introduction}

While no two financial crises are identical, most recent ones ${ }^{1}$ share (at least) three key features: currency peg: The exchange rate is fixed at an ambitious and ultimately unsustainable rate ${ }^{2}$ poor risk management: The corporate sector (banks and firms) is overly exposed to a depreciation of the local currency, and thus suffers from "original sin" $;^{3}$ sudden stop: Capital inflows, initially large, rapidly come to a sudden halt. ${ }^{4}$

These familiar observations raise a host of nagging questions:

- Why do so many countries peg and floaters manage their exchange rate ${ }^{5}$ if capital mobility makes exchange rate management hazardous?

- Why does the corporate sector choose to be exposed to exchange rate risk and the concomitant threat of facing liquidity shortages? Or, even more basically, why do domestic residents not enter into insurance contracts with foreigners in which the latter would deliver dollars in bad times and receive dollars in good times?

- Why do international financial institutions not take more advantage of the post-crisis depreciated exchange rate to invest in the country?

This paper suggests a common signaling hypothesis as a potential answer to these questions.

Premises: The paper builds a simple, micro-founded model of exchange rate management, speculative attacks, and exchange rate determination, on the following premises:

a) The domestic government is privately informed about variables, including its own political intentions, that affect the future exchange rate: the level of reserves (broadly defined to account for the State's off-balance sheet liabilities or the quality of reserves tied in contracts or in commodities); the political support necessary to sustain the currency's value; the government's willingness to implement structural reforms, deal with corruption or protect property rights; or the level of fiscal needs.

b) The government has preferences over exchange rates. This paper analyzes the case in which the government benefits from the market's perception of a strong currency, say because this facilitates its firms' access to the international capital market (which we will use for

\footnotetext{
${ }^{1}$ E.g., Mexico (1994), Southeast Asia (1997), Russia (1998), Brazil (1999) and Argentina (2001).

${ }^{2}$ See, for example, Fischer (2001) and Summers (2000).

${ }^{3}$ See Eichengreen and Hausmann (1999).

${ }^{4}$ See Calvo and Reinhart (2000).

${ }^{5}$ See Calvo and Reinhart (2002).
} 
illustration) or because domestic voters infer that the country is well-managed (see Section 8). As we discuss in the conclusion, the government's demand for a strong currency, which we endogenize, is of course not the only case of interest, but it is certainly the relevant one for countries that underwent financial crises and motivate this paper.

c) A peg is a mechanism by which the country exposes itself to incur welfare losses (or gains) that depend on the strength of its fundamentals. The government can pick an ambitious peg in an attempt to signal a strong currency and thereby attract foreign capital. The peg however triggers speculative attacks that the country must withstand for the signal to remain credible. Maintaining the peg is costly to a country with an overvalued currency as it must sell the foreign currency at an unfavorable rate, which will later on reduce the country's standard of living.

d) Exchange rate management is only one component of a cluster of policy signals. The government's equilibrium policy choices ought to be coherent in that it is irrational for the government to expend resources on policy $\mathrm{A}$ in an attempt to signal a strong currency and to simultaneously undo the signal through policy B. In this spirit, we endogenize the domestic residents' ability to hedge foreign exchange risk and, thereby, the source of exchange rate volatility (models of currency risk usually implicitly assume that hedging contracts are for some reason limited). We ask whether the government optimally facilitates or hinders such hedging. Similarly, we ask whether the government would like to use policy to alter the private sector's liability maturity structure.

Modeling: Let us describe first the paper's methodological contribution and then the economic insights. On the methodological front, we attempt to push the research agenda of second-generation models of rational speculation and exchange rate crises one step further by endogeneizing the choice of peg as well as the post-speculative-attack exchange rate. 
The general environment studied in this paper is summarized in Figure 1.

\begin{tabular}{|c|c|c|c|}
\hline \multicolumn{3}{|c|}{ Date 1} & Date 2 \\
\hline $\begin{array}{l}\text { - Government } \\
\text { has private } \\
\text { information } \\
\text { about } \\
\text { fundamentals } \\
\sigma \text { (strong with } \\
\text { probability } \rho \text {, } \\
\text { weak with } \\
\text { probability } \\
1-\rho \text { ). } \\
\text { - Peg } e \text { (choice } \\
\text { or legacy). }\end{array}$ & 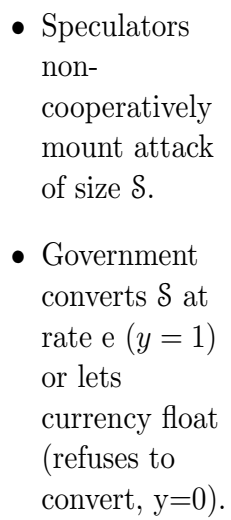 & $\begin{array}{l}\text { - Markets } \\
\text { update beliefs: } \\
\rho^{\prime}=\rho^{\prime}(y) \text {. } \\
\text { - Third party } \\
\text { action } \\
\text { depends on } \rho^{\prime} \text {. }\end{array}$ & $\begin{array}{l}\text { - Foreign } \\
\text { exchange } \\
\text { market clears. }\end{array}$ \\
\hline
\end{tabular}

Figure 1.- General Structure.

Capturing premise a), the government knows the fundamentals $\sigma$ while other economic agents only have a probability distribution: fundamentals are strong with probability $\rho$ and weak with probability $1-\rho$. The exchange rate, defined as the number of units of non-tradables needed to purchase one unit of tradables,${ }^{6}$ is then chosen by the government; alternatively, it could be the outcome of legacy arrangements. Speculators then rationally, but non-cooperatively mount a speculative attack: they demand the conversion of $\mathcal{S}$ pesos into dollars at the pegged exchange rates, where $\mathcal{S}$ is bounded above by their peso assets if short sales are infeasible, and is unbounded otherwise. The government then decides to convert $(y=1)$, i.e. defend the peg, or refuse to convert $(y=0)$, i.e. let the currency float. Observing the government's behavior, economic agents update their probability that fundamentals are strong from $\rho$ to $\rho^{\prime}$.

The key feature is that posterior beliefs $\rho^{\prime}$ matter; they influence some "third party decision." This third party decision may refer to any private sector decision that the government cares about. For concreteness, we will give two illustrations of such decisions, but the approach encompasses a variety of environments. The foreign exchange market clears at rate $e_{2}$ at the final date 2 , when fundamentals are revealed.

Our model, in reduced form, has two equations:

\footnotetext{
${ }^{6}$ By abuse of language, we will sometimes identify tradables as "dollars" and non-tradables as "pesos."
} 
- Government's objective function: Labelled $W$, it takes the form:

$$
W=\phi\left(\rho^{\prime}\right)+v\left(e_{2}\right)
$$

where $\phi$ is increasing (the government prefers a strong currency) and $v$ is decreasing (a devalued currency reduces the consumers' purchasing power).

- Exchange rate determination: The date-2 exchange rate

$$
e_{2}=\psi\left(\sigma, L, \rho^{\prime}\right)
$$

is decreasing in the fundamentals $\left(\frac{\partial \psi}{\partial \sigma}<0\right.$ ), and increasing in the loss (or gain if negative) to speculators:

$$
L=y \mathcal{S}\left(\frac{1}{e}-\frac{1}{e_{2}}\right)
$$

In the first, but not the second application, $e_{2}$ also depends on posterior beliefs at date 1.

Behavior follows a perfect Bayesian equilibrium: speculation maximizes the speculator's profit given subsequent expected government behavior; the government optimizes given the size $\mathcal{S}$ of the attack and given the predicted impact of a defense or abandonment of the currency on market beliefs $\rho^{\prime}$; and finally, the market updates beliefs about fundamentals according to Bayes rule and equilibrium strategies.

In our first illustration, third parties are foreign investors, whose investment in domestic firms increases with their perception of strength of the currency. The government then attaches particular importance to these beliefs $\rho^{\prime}\left(\frac{d \phi}{d \rho^{\prime}}\right.$ is high) when it is closely related to corporate interests and corporate borrowers benefit from an increased access to international capital markets.

In the second illustration, third parties are domestic voters, who are more likely to reelect the government if the latter's past management, as measured by the fundamentals, is perceived to have brought wealth (in the form of international collateral) to the country, and therefore future purchasing power to consumers. The government then attaches particular importance to beliefs $\rho^{\prime}$ when re-election concerns are strong (the election is near and disputed).

Note that in our model there is no "fundamental exchange rate" to which the currency returns after the speculative attack; indeed, the post-speculative-attack exchange rate depends on the peg's ambition, the size of the speculative attack, and the government's response to it. An attack on an undervalued (overvalued) currency further appreciates (depreciates) its long-term value. Relatedly, that speculative attacks make the country wealthier when the 
currency is undervalued implies that we cannot assume that defending the peg is systematically costly. Nor do speculative activities always exhibit strategic complementarity (meaning that a larger attack by other speculators increases one's incentive to attack the currency).

Accordingly, we identify three factors of strategic complementarity (SC) or substitutability (SS): two "wealth effects" and a "speculator's curse effect." The two wealth effects have already been described: speculation has an immiserizing effect on a country with weak fundamentals and a windfall gain effect on a country with strong fundamentals. The former is conducive to SC and the latter to SS. The speculator's curse effect relates to the government's response: A more massive attack makes it more likely that a country with weak fundamentals lets the currency float. Speculators are therefore more likely to sell pesos when the latter are valuable. The speculator's curse effect is a factor of SS.

Insights: Besides these modelling points, the paper's main economic insights are:

(1) While many experts argue against fixed rates in the presence of capital mobility on normative grounds, in our positive model, it is precisely capital mobility that confers a signaling value upon exchange rate management and generates equilibrium pegs. There is thus no tension between the normative stance against pegs in a world of capital mobility and a government's rational demand for pegging.

(2) Hedging is endogenously incomplete. To be credible in its attempt at convincing the market of the currency's strength, the government cannot encourage, and actually must discourage hedging by residents. Letting the residents hedge is a clear admission that the currency is overvalued by the market and makes any complementary attempt at exchange rate management futile.

(3) Performing comparative statics with respect to the government's objective function, the model corroborates on the theoretical front empirical work finding that pegs are more likely to be maintained before an election, and less likely to be maintained, the larger the tradable goods sector.

(4) An increased government concern for attracting foreign capital leads to a more ambitious peg.

(5) The peg is likely to be more ambitious and a financial crisis more likely to happen if foreign speculators cannot sell the currency short.

(6) A peg may make domestic borrowers eager to issue short-term liabilities so as to provide foreign investors with an advantageous exit option. Furthermore, the government does not incentivize firms to lengthen the maturity structure even when it wants to, because doing so would again be an open admission of a future depreciation. This result, in conjunction with (2), predicts a co-determination of pegging and original sin and is 
in line with the recent empirical evidence due to Eichengreen, Hausmann and Panizza (2002) and Alesina and Wagner (2003) according to which original sin is positively correlated with managed floating and fixing. ${ }^{7}$

Related literature- Our work is related to many strands of literature. The signaling approach here is connected to several other papers that study policy signaling in an open economy (i.e. Drazen and Masson (1994), Bartolini and Drazen (1997), and Drazen (2001)). Drazen and Masson show how the public may learn from policy the strength of the government's aversion to inflation. Bartolini and Drazen argue that capital account liberalization can send a favorable signal to market participants, which in turn leads to capital inflows. The focus of this paper on pegs, speculative attacks and original sin is rather different, though.

Only a few papers in international finance explicitly allow hedging by domestic residents. Lack of hedging by firms has been explained in a variety of ways, however. Jeanne (1999) reasons that dollar-denominated debt can signal strength for borrowers, while Jeanne (2001) argues that dollar-denominated debt may be less risky in an environment where the monetary authority lacks credibility. Chamon and Hausmann (2002) present a model where borrowers expect others to borrow in dollars and optimal monetary policy is forced to fulfill those expectations. Tirole (2003) shows how dollar debt affects government incentives and may constrain moral hazard. Finally, soft budget constraint problems may lead banks to gamble on a government bailout (see McKinnon and Pill (1997) and Schneider and Tornell (2003)). In particular, Ranciere, Tornell and Westermann (2003) present a model where consumers and firms can hedge all exchange rate risk and there is endogenous financial fragility because of systemic bailout guarantees. The systemic bailout guarantees literature leaves open the question of why there is inadequate prudential regulation in the domestic banking system rather than more efficient transfers to the government's banking friends. This paper makes the government's reluctance to let banks and other residents borrow in domestic currency or enforce prudential regulation an integral part of a signaling strategy.

The literature on exchange rate regimes is immense and will not be surveyed here. ${ }^{8}$ Some common arguments in favor of fixed rates are that they reduce transaction costs and discourage noise traders (Jeanne and Rose (2002)), they serve as policy commitments (Giavazzi and Pagano (1988)), and help governments gain monetary credibility (Herrendorf (1999)). However, Tornell and Velasco (2000) contend that fixed exchange rates may delay the impact of fiscal policy and therefore might provide bad incentives for a short-sighted

\footnotetext{
${ }^{7}$ See also Reinhart, Rogoff and Savastano (2003) who document a link between current levels of dollarization and countries past reliance on exchange rate controls.

${ }^{8}$ See Ghosh, Guide and Wolf (2003) for a recent survey.
} 
fiscal authority.

Following seminal contributions by Krugman (1979) and Obstfeld (1996) among others, this paper contributes to the currency crises literature since speculation in the model influences the choice of the exchange rate regime. A focus of our analysis, like Cukierman, Goldstein and Spiegel (2004), is to endogenize the level of the peg. Cukierman et. al. study the strategic interaction between the ex ante choice of exchange rate regime and the likelihood of ex post currency attacks in a country that is vulnerable to a speculative attack. Their paper relies on a reduced-form macroeconomic structure following Morris and Shin (1998)'s classic paper. This paper, on the other hand, provides a micro-founded model of exchange rate management which shows how defending the peg is costly and might actually be profitable and when to expect strategic complementarities and positive externalities in speculation. In this framework, the post-speculation exchange rate is also contingent on a loss of reserves and depends on the speculative attack and exchange rate management.

The idea that the choice of exchange rate regime and its management arbitrates between (primarily) domestic interest groups has been frequently discussed in case studies and, more recently, in cross-sectional empirical analysis. See Eichengreen (1995) and Frieden (1997) for examples of the former and Alesina and Wagner (2003), Eichengreen, Hausmann, and Panizza (2002), and Levy-Yeyati, Sturzenegger and Reggio (2003) for examples of the latter. We will later discuss this evidence.

\section{Model}

The model has two periods: $t=1,2$ and four types of agents: domestic entrepreneurs/firms, domestic consumers, foreign investors/foreign speculators, and the government.

Let "** denote tradable good. The utility function of foreign investors or speculators is given by:

$$
U^{\text {foreigners }}=c_{1}^{*}+c_{2}^{*},
$$

while that of domestic residents and entrepreneurs is

$$
U^{\text {domestic }}=c_{1}+c_{2}+u\left(c_{2}^{*}\right),
$$

where $u(\cdot)$ is strictly concave (unless otherwise stated) and $u\left(c_{2}^{*}\right)=-\infty$ for $c_{2}^{*} \leq 0$. Let $e_{2}$ denote the date-2 exchange rate in units of pesos per dollar, so a strong exchange rate corresponds to a low $e_{2}$. The domestic residents' and entrepreneurs' date- 2 consumption of tradables, $c_{2}^{*}\left(e_{2}\right)$, is given by:

$$
\max _{c_{2}^{*}}\left\{u\left(c_{2}^{*}\right)-e_{2} c_{2}^{*}\right\}
$$


Let $v\left(e_{2}\right) \equiv u\left(c_{2}^{*}\left(e_{2}\right)\right)$ denote the consumer's gross surplus from consuming tradables. $v$ is a decreasing function.

Let us first describe the timing, and then discuss the modelling elements.

\section{Timing:}

(a) A pre-determined level of foreign-owned liabilities (in pesos) $D$ is due at date 1 .

Date 1:

(b) Government privately learns foreign reserves $\mathcal{R}$ which are either $\mathcal{R}_{s}$ with probability $\rho$ or $\mathcal{R}_{w}$ with probability $1-\rho$, where $\mathcal{R}_{s}>\mathcal{R}_{w}$.

(c) Government chooses exchange rate $e$.

(d) $D$ is repaid to foreign investors.

Foreign speculators take $\mathcal{S}$ out of the country. $\mathcal{S}$ is the size of the attack, which we allow to be either be unbounded (unlimited short sales) or bounded by D (no short sales).

The government observes $\mathcal{S}$ and maintains the peg (converts $\mathcal{S}$ at rate $e$ ) or lets the currency float by refusing to convert.

(e) The foreign exchange market updates its beliefs to $\rho^{\prime}$, which depends on whether the government maintained the peg. The forward exchange rate is denoted $f$. Domestic entrepreneurs finance equipment in tradables by borrowing abroad at rate $f$.

Date 2:

(f) Entrepreneurs produce non-tradables, the foreign exchange market clears (the remaining reserves are equal to the net demand for tradables), and consumption takes place. 


\begin{tabular}{|c|c|c|c|c|c|}
\hline (a) & (b) & (c) & $\begin{array}{l}\text { ate } 1 \\
\\
\end{array}$ & (e) & $\begin{array}{c}\text { Date } 2 \\
\text { (f) }\end{array}$ \\
\hline $\begin{array}{l}\text { Initial } \\
\text { foreign } \\
\text { debt (in } \\
\text { non- } \\
\text { tradables) } \\
D \text { due at } \\
\text { date } 1 .\end{array}$ & $\begin{array}{l}\text { Government } \\
\text { privately } \\
\text { learns foreign } \\
\text { reserves. }\end{array}$ & $\begin{array}{l}\text { Government } \\
\text { chooses } \\
\text { exchange } \\
\text { rate } e \text {. }\end{array}$ & $\begin{array}{l}\text { - Speculators } \\
\text { non- } \\
\text { cooperatively } \\
\text { mount } \\
\text { speculative } \\
\text { attack } \mathcal{S} \text {. } \\
\text { - Government } \\
\text { observes } \mathcal{S} \\
\text { and } \\
\text { maintains } \\
\text { peg } \\
\text { (converts } \mathcal{S} \\
\text { at rate e) or } \\
\text { lets } \\
\text { currency } \\
\text { float } \\
\text { (refuses to } \\
\text { convert). }\end{array}$ & $\begin{array}{l}\text { - The market } \\
\text { updates its } \\
\text { beliefs to } \rho^{\prime} \text {. } \\
\text { The forward } \\
\text { rate is } \frac{1}{f}= \\
E_{\rho^{\prime}}\left[\frac{1}{e_{2}}\right] \text {. } \\
\text { - Domestic } \\
\text { en- } \\
\text { trepreneurs } \\
\text { finance } \\
\text { projects } \\
\text { using } \\
\text { tradables by } \\
\text { borrowing } \\
I(f) \text {. }\end{array}$ & $\begin{array}{l}\text { - } \text { Entrepreneurs } \\
\text { produce non- } \\
\text { tradables, } \\
\text { and pay back } \\
r I(f) \text { to for- } \\
\text { eign investors. } \\
\text { - Foreign ex- } \\
\text { change market } \\
\text { clears at ex- } \\
\text { change rate } \\
e_{2} \text { - Consumption } \\
\text { takes place. }\end{array}$ \\
\hline
\end{tabular}

Figure 2.- Timing.

Let us discuss the modelling assumptions:

At stage (a), the existence of an initial debt $D$ in pesos establishes a lower bound on the volume of funds that can be mobilized for a speculative attack: when reimbursed at date 1 , foreign investors can roll over or take the money out of the country. $D$ could also denote the amount of money that foreigners could obtain by selling their equity portfolio at date 1 or the peso-denominated collateral (e.g. real estate) seized by holders of dollar debt in defaulting firms. ${ }^{9}$ In order to abstract away from balance-sheet effects, assume that this debt is paid by parties who are private and are different from the entrepreneurs who will need to raise funds at substage (e). We will focus on two polar cases: in the absence of short sales by foreigners, $0 \leq \mathcal{S} \leq D$. With costless short selling of the currency by foreigners, $0 \leq \mathcal{S}<\infty .{ }^{10}$ The motivation for introducing initial debt $D$ in the model is two-fold. First, $D$, as discussed above, serves as an upper bound for speculation when short sales are infeasible. Second, we will later endogenize debt maturity, i.e. whether foreign lenders prefer to be repaid at date

\footnotetext{
${ }^{9}$ Dollar debt that is repaid to investors can be directly counted in $\mathcal{R}$ and so we do not need to consider it.

${ }^{10}$ More generally, we could consider convex costs of short selling as in Drazen (2000).
} 
1 or date 2 (Section 7 ).

At stage (b), the government acquires private information about its type. Assuming that the government has private information about foreign reserves is a simple way to assume that the government has private information about a variable that will affect the date2 exchange rate: international collateral of public enterprises, willingness to implement structural reforms, off-balance sheet liabilities, forthcoming export promoting policies, fiscal needs (leading to a taxation of private international collateral), etc. For simplicity, the country is "strong" (has reserves $\mathcal{R}_{s}$ ) with probability $\rho$ and is "weak" (has reserves $\mathcal{R}_{w}$ ) with probability $1-\rho$ where $\mathcal{R}_{s}>\mathcal{R}_{w} \cdot{ }^{11}$

At stage (c), the choice of the exchange rate is per se costless, as setting a peg at stage (c) and letting the currency float at stage (d) is, for given beliefs, equivalent to not setting the peg. Accordingly, we will look for an equilibrium where there is full pooling at stage (c). Alternatively, the peg is driven by legacy arrangements (the peso can be exchanged one-for-one for dollars), and there is no stage (c).

At stage (d), speculators are competitive: they individually do not affect the volume of speculative movements, and therefore the government's decision of whether to defend the currency. We do not set an arbitrary upper bound on the size of the speculative attack that the government can resist. In other words, we assume for simplicity that the government can (possibly secretly) borrow in the market to resist the attack. This assumption is particularly relevant in the case of costless short sales.

At stage (e), the market puts posterior probability $\rho^{\prime}$ on fundamentals being strong. The forward rate is $f$ where

$$
\frac{1}{f}=E_{\rho^{\prime}}\left[\frac{1}{e_{2}}\right]
$$

Domestic entrepreneurs borrow $I(f)$ in tradables (with $I^{\prime}<0$ ) from foreigners. The proceeds of this investment at date 2 will be in non-tradables, of which $r I(f)$ will be returned back to foreign investors. Here the entrepreneur borrows in domestic currency, and the foreign lenders will need to convert into dollars at date 2. Equivalently, the foreign lenders can hedge the exchange rate risk at date 1 or the entrepreneur could borrow in dollars and hedge or not the exchange rate risk. Because we are not interested in default, all arrangements are equivalent.

Last, at date 2, the government's foreign reserves or whatever will remain of them after the speculative attack will be sold in the market at date 2 in the exchange of non-tradables,

\footnotetext{
${ }^{11}$ Alesina and Wagner (2003) hypothesize that virtuous countries avoid floating to "signal rigor" and document that countries with poor political institutions are less able to stick to a pegged exchange rate. Similarly, in his discussion of Venezuela in the late 90s, Corrales (2000) argues that since the exchange rate "is one of the most visible and highly watched prices in any developing economy ... [it is] an ideal signaling device."
} 
and the proceeds distributed equally among domestic residents. ${ }^{12}$ Pesos that are not used to attack the peg $\left(D-\delta y_{i}\right)$ remain in the country between period 1 and period 2 , and are repatriated by foreigners in period 2 , at rate $e_{2}$.

The market-clearing equation for type $i \in\{w, s\}$ at date 2 is:

$$
\mathcal{R}_{i}-\frac{\mathcal{S} y_{i}}{e}-\frac{D-\mathcal{S} y_{i}}{e_{i}}=c_{2}^{*}\left(e_{i}\right)+\frac{r}{e_{i}} I(f),
$$

where $y_{i}=1$ if type $i$ defends the peg and $y_{i}=0$ if it lets the currency float.

Finally, the government's objective function is assumed to take the following form:

$$
W=\pi(I, \alpha)+v\left(e_{2}\right),
$$

where $\alpha$ is a parameter indexing the weights attached to investment,

$$
\frac{\partial \pi}{\partial I}>0 \quad \text { and } \quad \frac{\partial^{2} \pi}{\partial \alpha \partial I}>0
$$

The government's welfare improves when there is greater investment and the size of the improvement is increasing in the weight the government places on domestic entrepreneurs. The size of $\alpha$ governs the tension between entrepreneurs and residents in the government's objective function. It is this competition between political stakeholders that we seek to exploit in this model. ${ }^{13}$

Equations (1), (2), and (3) together with rational speculation (see below), summarize the description of the model. Note also that the (sub)game with stage (c) omitted is of independent interest. Indeed it depicts the case in which the exchange rate has been pegged and need no longer be optimal following a shock.

\section{Corporate finance example}

Let us show how the government's objective function (3) results from a simple weighting of corporate and non-corporate interests with a standard corporate finance determination of investment. (The specific functional form analyzed in this example will be used only in Propositions 5 and 8 and so the reader may skip this example). ${ }^{14}$

\footnotetext{
${ }^{12}$ The assumption that the proceeds are distributed equally among domestic residents is not essential and while the government's objective function would take a slightly different form with unequal distributions, the qualitative results would remain the same.

${ }^{13}$ For instance, because of a strong peso, Kessler (2000) states that the middle class in Mexico benefitted from the subsidized consumption of imported groceries and luxury items, durables, travel and manufactured goods made with foreign inputs.

${ }^{14}$ Kessler (2000) says that a strong peso in Mexico subsidized the ability of the corporate sector to borrow abroad and accounts for the government's reluctance to devalue.
} 
A fraction $\gamma$ of residents are entrepreneurs and a fraction $1-\gamma$ non-entrepreneurs (called "consumers"; naturally entrepreneurs also consume). The government puts weight $\alpha$ on the utility of the representative entrepreneur and 1 on the utility of the representative consumer. The proceeds are distributed equally among domestic residents. Thus the government's objective function is:

$$
W_{G}=\alpha \gamma U^{\text {entrepreneurs }}+(1-\gamma) U^{\text {other residents }} .
$$

The representative entrepreneur has initial wealth $a$ in tradables, invests a variable $i$ tradables, and produces $R(i)$ units of non-tradables, $[R(i)-r i]$ of which are non-observable by the investors (and therefore appropriated by the entrepreneur, as in, say Bolton and Scharfstein (1990)), and $r i$ is collateral (such as real estate, etc.) that can be seized by investors. Let $R(\cdot)$ be concave. We focus on the case in which firms are financially constrained. ${ }^{15}$

Recalling that $f$ denotes the (forward) exchange rate at stage (e), the foreign investors' break-even condition is: ${ }^{16}$

$$
\frac{r i}{f}=i-a, \quad \text { or } \quad i=\frac{a}{1-\frac{r}{f}} .
$$

Let

$$
I(f) \equiv \gamma i=\frac{\gamma a}{1-\frac{r}{f}}
$$

denote per capita investment and note that the expectation of a strong currency facilitates financing.

Assuming that firms face solvency constraints is one way of generating rents for the corporate sector and therefore a political stake. Furthermore, the rents depend on the degree

\footnotetext{
${ }^{15}$ The equilibrium investment $i=\frac{a}{1-\frac{r}{f}}$ must thus be assumed to be smaller than investment $i^{*}$ that maximizes the entrepreneur's date- 2 peso wealth. Given that the entrepreneur must contribute $i\left(1-\frac{r}{f}\right)$ units of tradables at date $1, i^{*}$ solves:

$$
\max _{i}\left\{[R(i)-r i]-i\left(1-\frac{r}{f}\right) E\left(e_{2}\right)\right\},
$$

where $E\left[e_{2}\right]$ is the stage (e) expectation of the date-2 exchange rate and $\frac{1}{f}=E\left(\frac{1}{e_{2}}\right)$. Therefore,

$$
R^{\prime}\left(i^{*}\right)=E\left(e_{2}\right)-r\left[E\left(e_{2}\right) E\left(\frac{1}{e_{2}}\right)-1\right] .
$$

${ }^{16}$ This analysis presumes that the NPV is positive $\left(R^{\prime}(0)>E\left(e_{2}\right)-r\left[E\left(e_{2}\right) E\left(\frac{1}{e_{2}}\right)-1\right]\right)$, while the borrowing capacity is finite: $f>r$ which we will assume.
} 
of access to the international capital market, which itself depend on exchange rate anticipations. Alternatively, we could have introduced inframarginal rents through a decreasing returns technology. Our corporate finance approach, however, yields simpler expressions.

The government's net date- 2 reserves are $\mathcal{R}_{i}-\mathcal{S} y_{i}\left(\frac{1}{e}-\frac{1}{e_{i}}\right)$. From the market clearing equation (2), the peso proceeds are redistributed to domestic residents and therefore equal to $[D+r I(f)]+e_{2} c_{2}^{*}\left(e_{2}\right)$.

The government's objective function is:

$$
\begin{aligned}
W_{G}=\alpha \gamma & {\left[(R(i)-r i)+\left(r I+D+e_{2} c_{2}^{*}\right)+\left(u\left(c_{2}^{*}\right)-e_{2} c_{2}^{*}\right)\right] } \\
& +\left[-D+(1-\gamma)\left(r I+D+e_{2} c_{2}^{*}\right)+(1-\gamma)\left(u\left(c_{2}^{*}\right)-e_{2} c_{2}^{*}\right)\right],
\end{aligned}
$$

or

$$
W=\pi(I, \alpha)+v\left(e_{2}\right),
$$

where $W=\frac{W_{G}}{\alpha \gamma+1-\gamma}, v\left(e_{2}\right)=u\left(c_{2}^{*}\left(e_{2}\right)\right)$ and $\pi(I, \alpha)=\frac{\alpha \gamma R\left(\frac{I}{\gamma}\right)-r(1-\gamma)(\alpha-1) I+\gamma(\alpha-1) D}{\alpha \gamma+1-\gamma}$.

Notice that $\frac{\partial \pi}{\partial I}>0$ and $\frac{\partial^{2} \pi}{\partial \alpha \partial I}>0 .{ }^{17}$

\section{Benchmark: Full information}

Suppose that $\mathcal{R}$ is common knowledge. Then, rational expectations imply that the date- 2 exchange rate is perfectly foreseen by the market at date 1 . Let $e_{s}^{F I}$ and $e_{w}^{F I}$ stand for the exchange rate of the strong and weak type of government under full information. Investment is $I\left(e_{i}^{F I}\right)$ for $i=\{w, s\}$.

Under common knowledge about the future exchange rate, setting and defending an ambitious exchange rate (i.e., an exchange rate $e$ below the full information, floating level) reduces welfare. Furthermore, under floating, speculative trades are irrelevant; and so, clearing in the foreign exchange market is equivalent to:

$$
\mathcal{R}_{i}-\frac{D}{e_{i}^{F I}}=c_{2}^{*}\left(e_{i}^{F I}\right)+\frac{r}{e_{i}^{F I}} I\left(e_{i}^{F I}\right) .
$$

Since $\mathcal{R}_{s}>\mathcal{R}_{w}$

$$
e_{w}^{F I}>e_{s}^{F I}
$$

The government's utility under full information is:

$$
W_{i}^{F I}=\pi\left(I\left(e_{i}^{F I}\right), \alpha\right)+v\left(e_{i}^{F I}\right) .
$$

${ }^{17}$ To see this, recall from footnote 15 that $i \leq i^{*}$, where $i^{*}$ maximizes $[R(i)-r i]-i\left(1-\frac{r}{f}\right) E\left[e_{2}\right]$. Therefore, for the relevant range $i \leq i^{*}, R^{\prime}(i)>r$, or $\left.\frac{\partial \pi}{\partial I}\right|_{I=\gamma i} \propto \alpha R^{\prime}(i)-r(1-\gamma)(\alpha-1)>0$. Furthermore, $\left.\frac{\partial^{2} \pi}{\partial \alpha \partial I}\right|_{I=\gamma i} \propto$ $R^{\prime}(i)-r>0$. 


\section{Structure of Equilibrium}

Turning to incomplete information, we will look for perfect Bayesian equilibria of the game among the speculators and the government. The speculators' strategy will be a function $\mathcal{S}=\mathcal{S}(e)$ mapping the exchange rate peg $e$ into $[0, D]$ or $[0, \infty)$, depending on whether we allow short selling of the currency by foreigners. We focus on the case of short sales in the next section and then analyze no short sales in the following section.

The type $i$ government's strategy will be a probability distribution $y_{i}=y_{i}(\mathcal{S}, e)$ mapping, for arbitrary peg $e$, the volume of speculation $\mathcal{S}$ into $[0,1]$. When $\mathcal{S}=0$, defending or abandoning the peg is "cheap talk." We nevertheless need to define the government's strategy $y_{i}(0, e)$ at this level of speculation since in the absence of speculation, atomistic speculators must still know whether the government would convert the pegged exchange rate if they did speculate individually. Alternatively (and equivalently), we can define $y_{i}(0, e)$ as the limit of $y_{i}(\mathcal{S}, e)$ as $\mathcal{S}$ converges to 0 .

Let

$$
x_{i}(e) \equiv y_{i}(\mathcal{S}(e), e) .
$$

In what follows, we will impose a sorting condition, which will guarantee that the strong type strictly prefers to maintain the peg whenever the weak type is willing to do so. Thus, the focus will be on the weak type's probability of maintaining the peg; in order to simplify notation, we let

$$
x(e) \equiv x_{w}(e) .
$$

Our analysis rests on two technical assumptions. The other illustration (Section 8) does not require these two assumptions. We first need to assume that the government values capital inflows positively, at least over a range of parameters. Because foreign borrowing by non-tradable good sectors consumes reserves, it competes with consumption of tradables by consumers. It must therefore be the case that the government values corporate investment sufficiently.

Assumption 1: (demand for capital inflows)

The weak type prefers to pool rather than reveal its type when $\mathcal{S}=0$ :

$$
W_{w}^{F I}<\pi\left(I\left(e^{h m}\right), \alpha\right)+v\left(e_{w}\right),
$$

where $e^{h m} \in\left(e_{s}^{F I}, e_{w}^{F I}\right)$, the "harmonic mean" exchange rate, is defined by

$$
\frac{1}{e^{h m}} \equiv \frac{\rho}{e_{s}}+\frac{1-\rho}{e_{w}},
$$


and $e_{i}$ for $i=\{w, s\}$ satisfies:

$$
\mathcal{R}_{i}-\frac{D}{e_{i}}=c_{2}^{*}\left(e_{i}\right)+\frac{r}{e_{i}} I\left(e^{h m}\right) .
$$

Assumption 1 rules out the possibility that the weak type wishes to separate when there is no speculative attack and amounts, as we noted, to the imposition of a lower bound on $\alpha$. That is, it is satisfied if the government cares about its domestic entrepreneurs enough relative to its domestic residents ( since $\left.I\left(e^{h m}\right)>I\left(e_{w}^{F I}\right)\right)$.

Assumption 2: (sorting condition)

Fixing $(\mathcal{S}, e)$, the strong type is relatively more eager to defend the peg. Let $I$ and $\hat{I}$ denote arbitrary investment levels with $I \in\left[I\left(e_{w}^{F I}\right), I\left(e_{s}^{F I}\right)\right]$ and $\hat{I} \leq I$ and let $\hat{e}_{i}$ be given by:

$$
\mathcal{R}_{i}-\frac{D}{\hat{e}_{i}}=c_{2}^{*}\left(\hat{e}_{i}\right)+\frac{r}{\hat{e}_{i}} \hat{I},
$$

and $e_{i}$ be given by:

$$
\mathcal{R}_{i}-\frac{\mathcal{S}}{e}-\frac{D-\mathcal{S}}{e_{i}}=c_{2}^{*}\left(e_{i}\right)+\frac{r}{e_{i}} I
$$

then

$$
v\left(\hat{e}_{w}\right)-v\left(e_{w}\right) \geq v\left(\hat{e}_{s}\right)-v\left(e_{s}\right) .
$$

This condition will ensure that the strong type does not choose to float when the weak type does not either. The exchange rate $\hat{e}_{i}$ is the level corresponding to when the government chooses not to defend the currency, which generates a forward rate $f \in\left[e_{s}^{F I}, e_{w}^{F I}\right]$ and therefore investment $I(f) \in\left[I\left(e_{w}^{F I}\right), I\left(e_{s}^{F I}\right)\right]$.

We expect the sorting condition to hold because foreign reserves are more valuable to the weak type as there is a lower level of consumption of the tradable good. Also, the weak type wastes more money by maintaining the peg than the strong type.

Example: The sorting condition holds with $\log$ utility: $c_{2}^{*}\left(e_{2}\right)=\frac{1}{e_{2}}$ and $v\left(e_{2}\right)=-\log \left(e_{2}\right)$. With log utility, exchange-rate clearing yields the following relations:

$$
\hat{e}_{s}=\hat{e}_{w} \frac{\mathcal{R}_{w}}{\mathcal{R}_{s}} \quad \text { and } \quad e_{s}=e_{w} \frac{\mathcal{R}_{w}-\frac{\mathcal{s}}{e}}{\mathcal{R}_{s}-\frac{s}{e}}
$$

Because

$$
\frac{\mathcal{R}_{s}-\frac{\mathcal{s}}{e}}{\mathcal{R}_{w}-\frac{\mathcal{s}}{e}} \geq \frac{\mathcal{R}_{s}}{\mathcal{R}_{w}}
$$




$$
v\left(\hat{e}_{w}\right)-v\left(e_{w}\right) \geq v\left(\hat{e}_{s}\right)-v\left(e_{s}\right)
$$

One other definition will be convenient for characterizing the equilibrium. When the weak type government defends the currency with probability $x$ and therefore the strong type defends the currency with probability 1 , we let

$$
\rho^{\prime}(x) \equiv \frac{\rho}{\rho+(1-\rho) x}
$$

denote the posterior beliefs that a government that defends the currency is strong.

Proposition 1: ${ }^{18}$ If $e_{s}^{F I}<e<e_{w}^{F I}$, then for all $\mathcal{S}>0, e_{s}<e_{s}^{F I}$ and $e_{w}>e_{w}^{F I}$, where $e_{s}$ and $e_{w}$ are the date-2 exchange rates of the strong and weak types when the government has defended the peg.

When the peg undervalues the currency in view of strong fundamentals, the exchange rate appreciates relative to the full information case for two reasons: First, the capital inflow is smaller and so the country's debt burden is alleviated. Second, the government makes a windfall profit when defending the peg $\left(e>e_{s}\right)$, which concurs to make the currency even stronger. Conversely, when the peg overvalues the currency because fundamentals are weak, the weak type's exchange rate depreciates for the same, but opposite two reasons.

\section{Strategic complements or substitutes?}

Many models of currency crises (i.e. Obstfeld (1996) and Morris and Shin (1998)) emphasize that speculative attacks may be self-fulfilling because of strategic complementarities in the speculators' behavior. In our model, whether speculative activities are strategic complements or strategic substitutes depends on the strength of the prior beliefs. Here, speculative activities exhibit strategic complementarity (substitutability) if a higher volume of speculation makes a speculator more (less) willing to convert pesos into dollars. Strategic complementarity (SC) is equivalent to the forward rate increasing with $\mathcal{S}$. Strategic substitutability (SS) is equivalent to the forward rate decreasing with $\mathcal{S}$. Still, two possible definitions of strategic complementarity /strategic substitutability can be offered. The first, which we will use for our purposes, takes the government's currency defense strategy as given:

Definition 1. For a given peg e and an arbitrary $\rho$ (not necessarily the prior), let $f_{\rho}(\mathcal{S})$ be defined by:

$$
\frac{1}{f_{\rho}(\mathcal{S})} \equiv \frac{\rho}{e_{s}}+\frac{1-\rho}{e_{w}}
$$

\footnotetext{
${ }^{18}$ All proofs are gathered in the appendix.
} 
and

$$
\mathcal{R}_{i}-\frac{\mathcal{S}}{e}-\frac{D-\mathcal{S}}{e_{i}}=c_{2}^{*}\left(e_{i}\right)+\frac{r}{e_{i}} I\left(f_{\rho}(\mathcal{S})\right), \quad \text { for } \quad i \in\{w, s\}
$$

Speculative activities exhibit strategic complementarity (strategic substitutability) when $f_{\rho}(\mathcal{S})$ is increasing (decreasing) in $\mathcal{S}$, i.e. when a large speculative attack triggers an immediate depreciation of the currency, keeping the government's strategy fixed.

Alternatively, one could further include the government's reaction into the definition of SC/SS:

Definition 2. For a given peg e, let $f(\mathcal{S})$ be defined by:

$$
\frac{1}{f(\mathcal{S})} \equiv \frac{\rho^{\prime}(\mathcal{S})}{e_{S}}+\frac{1-\rho^{\prime}(\mathcal{S})}{e_{w}},
$$

where $\rho^{\prime}(\mathcal{S})=\frac{\rho}{\rho+(1-\rho) y_{w}(e, \mathcal{S})}, y_{w}(e, \mathcal{S})$ is the weak type's equilibrium probability of maintaining peg e when facing attack $\mathcal{S}$, and

$$
\mathcal{R}_{i}-\frac{\mathcal{S}}{e}-\frac{D-\mathcal{S}}{e_{i}}=c_{2}^{*}\left(e_{i}\right)+\frac{r}{e_{i}} I(f(\mathcal{S})), \quad \text { for } \quad i \in\{w, s\} .
$$

Speculative activities exhibit strategic complementarity (substitutability) when $f(\mathcal{S})$ is increasing (decreasing) in $\mathcal{S}$.

As discussed in the introduction, Definition 2 embodies the speculator's curse, provided that the weak type is less willing to defend a larger speculative attack and is therefore conducive to SS. Proposition 2 obtains sufficient conditions for SC/SS according to Definition 1:

Proposition 2: For $e_{s}^{F I}<e<e_{w}^{F I}$, there exists $\overline{\mathcal{S}}>D, \rho_{1}$, and $\rho_{2}$ such that $0<\rho_{1}<\rho_{2}<1$, such that speculative attacks exhibit, on $[0, \overline{\mathcal{S}}], S C$ if $\rho \in\left[0, \rho_{1}\right]$ and $S S$ if $\rho \in\left[\rho_{2}, 1\right]$.

The intuition behind Proposition 2 is straightforward. As we have already observed, an increase in the size of the speculative attack generates wealth effects: an immiserizing one for the weak type, whose currency is overvalued, and a windfall gain for the strong type, whose currency is undervalued. The impact on the forward rate depends on which of these effects dominates, and therefore on the beliefs. The bound $\overline{\mathcal{S}}$ on the speculative activities is just meant to guarantee that the weak (strong) type's exchange rate does not go to infinity (zero), and so exchange rates remain bounded; this bound can therefore be taken quite 
large. ${ }^{19}$

Example: Suppose the utility for tradables is strictly concave until some level $c_{0}^{*}$, at which it becomes linear:

$$
u\left(c^{*}\right)=u\left(c_{0}^{*}\right)+\left(c^{*}-c_{0}^{*}\right) \quad \text { for } c^{*} \geq c_{0}^{*} .
$$

Assume that $\mathcal{R}_{s}$ is very large, so consumption of tradables in the relevant range is always in the risk neutral part and

$$
e_{s}=1 \text {. }
$$

By contrast, $\mathcal{R}_{w}$ is small, and therefore $e_{w}>1$ in the relevant range. Speculative attacks have an immiserizing effect on the weak type (provided it defends the exchange rate), but do not lead to an appreciation of the strong type's exchange rate. Thus, speculative activities are necessarily SC in the sense of Definition 1. This result does not contradict Proposition 2, which presumed strict concavity of $u(\cdot)$ and therefore allowed an appreciation of the strong type's exchange rate due to speculative activities.

\section{Unlimited Short Sales}

With unlimited short sales, the forward rate when the peg is defended must be equal to the peg $(f=e)$. Suppose it were higher $(f>e)$; because speculators' profit is determined by what happens when the peg is defended (from an individual standpoint, a speculative trade that is not converted is equivalent to no speculative trade), the expectation of an average devaluation conditional on the peg being defended would trigger $\mathcal{S}=\infty$. Conversely, if $f<e$, foreign investors would invest an infinite amount in the country.

\subsection{Speculative attack and response for a given peg}

It is convenient to decompose the range of pegs into three regions, defined by the strong type's full-information exchange rate $e_{s}^{F I}$ and the prior exchange rate, defined by the harmonic mean $e^{h m}$, in the absence of speculation defined above.

a) Unambitious pegs: $e \geq e^{h m}$

\footnotetext{
${ }^{19}$ While successful speculative attacks often capture the headlines, many attacks fail when the government is perceived as sufficiently strong. For instance, Corrales (2000) argues that the Venezuelan central bank's ability to defend against a speculative attack severely hurt those who had borrowed bolivars to buy dollars.
} 
For $e \geq e^{h m}$, it is an equilibrium for the government to maintain the peg and for speculators not to attack. If, in the absence of speculation (or for small speculation), the government indeed defends the currency regardless of its type $(x(0)=1)$, then speculators are better off not converting pesos into dollars at the weak pegged exchange rate. Conversely, facing no or small speculation, the government prefers to defend the currency, keep market beliefs at the prior level $\rho$, and attract investment $I\left(e^{h m}\right)$ rather than abandoning the peg, being perceived as a weak type, and attract only $I\left(e_{w}^{F I}\right)$, as guaranteed by Assumption 1 for the weak type and (together with the sorting condition applied to $\hat{I}=I\left(e_{w}^{F I}\right), I=I\left(e^{h m}\right)$, and $\mathcal{S}=0$ ) for the strong type.

b) Ambitious pegs: $e_{s}^{F I} \leq e<e^{h m}$

With a more ambitious peg, speculation is strictly profitable, and therefore infinite in the absence of constraints on short sales, whenever the government defends the currency for sure. In this region, therefore, the peg may be abandoned with positive probability by the weak type: $x(e) \leq 1$. Furthermore, $\mathcal{S}>0$ : otherwise the weak type would "defend" the currency from Assumption 1.

Assume first that the weak type is indifferent between abandoning the peg, thereby leading to a depreciation of the currency to level $e_{w}^{F I}$, and maintaining the peg:

$$
W_{w}^{F I}=\pi(I(f), \alpha)+v\left(e_{w}\right) .
$$

Because $f=e$, equation (6) sets the date-2 exchange rate of the weak type when defending the currency. The market-clearing equation for the weak type then determines the level of speculative activity $\mathcal{S}$ :

$$
\mathcal{R}_{w}-\frac{\mathcal{S}}{e}-\frac{D-\mathcal{S}}{e_{w}}=c_{2}^{*}\left(e_{w}\right)+\frac{r}{e_{w}} I(f) .
$$

The strong type's date- 2 exchange rate in turn is given by the other market-clearing condition:

$$
\mathcal{R}_{s}-\frac{\mathcal{S}}{e}-\frac{D-\mathcal{S}}{e_{s}}=c_{2}^{*}\left(e_{s}\right)+\frac{r}{e_{s}} I(f) .
$$


Note that in this equilibrium, the level of investment, the posterior beliefs when the peg is defended, and the exchange rates are independent of the prior beliefs $(\rho)$ on the strong type. By contrast, when the country's initial reputation improves ( $\rho$ increases), the probability of defending the peg $(\rho+(1-\rho) x)$ increases as well.

Last, we need to determine the equilibrium probability of pooling by the weak type. The posterior beliefs $\rho^{\prime}(x)$ satisfy

$$
\frac{1}{f}=\frac{\rho^{\prime}(x)}{e_{s}}+\frac{1-\rho^{\prime}(x)}{e_{w}} .
$$

There exists a unique $x$ satisfying equation (9). If $x<1$, then we have an equilibrium. If not, then $x=1$ and $W_{w}^{F I} \leq \pi(I(f), \alpha)+v\left(e_{w}\right)$. The equilibrium determination is slightly different: $f=e,(7),(8)$, and (9), then give equilibrium.

In either case, $x(e)$ tends to 0 as $e$ converges from the right to $e_{s}^{F I}$. This demonstrates that, unlike in most signaling models, separation need not be costly (given costless short sales).

Under SC, if $x$ equals 1, speculation is infinite. Equilibrium behavior therefore requires that $x<1$. Thus the weak type must be indifferent between defending the currency and floating, which in turn requires a jump in $\mathcal{S}$ at $e=e^{h m}$. In turn, the jump in $\mathcal{S}$ implies that $x$ jumps downward as $e$ falls below $e^{h m}$ in order to keep speculators indifferent.

Under SS, by contrast, the increase in $\mathcal{S}$ as $e$ falls below $e^{h m}$ would lower $f$ implying $\mathcal{S}=0$, a contradiction. So as $e$ falls below $e^{h m}, x$ remains equal to 1 on some interval and $\mathcal{S}$ increases continuously.

c) Unsustainable pegs: $e \leq e_{s}^{F I}$

In this range, the speculative attack is infinite and both types abandon the peg.

Figure 3a depicts the equilibrium behavior for the SC case, while figure $3 \mathrm{~b}$ depicts the SS case: 


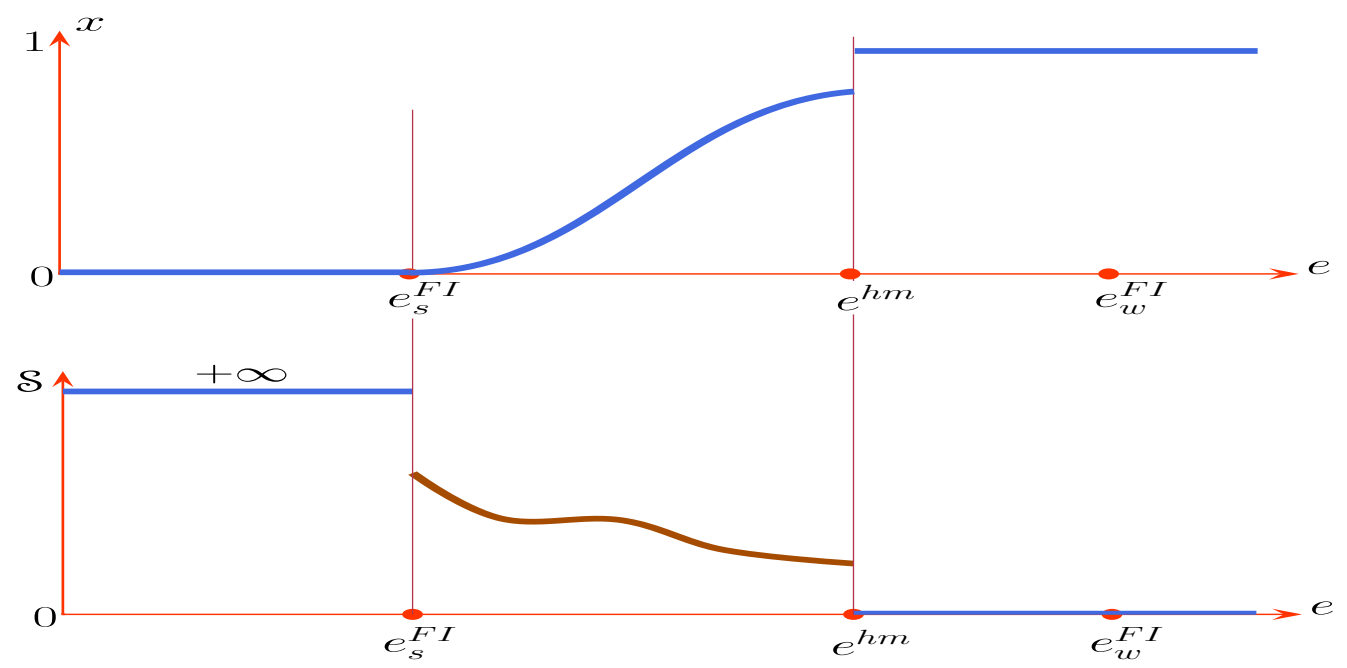

Figure 3a.- Equilibrium with Unlimited Short Sales (SC)

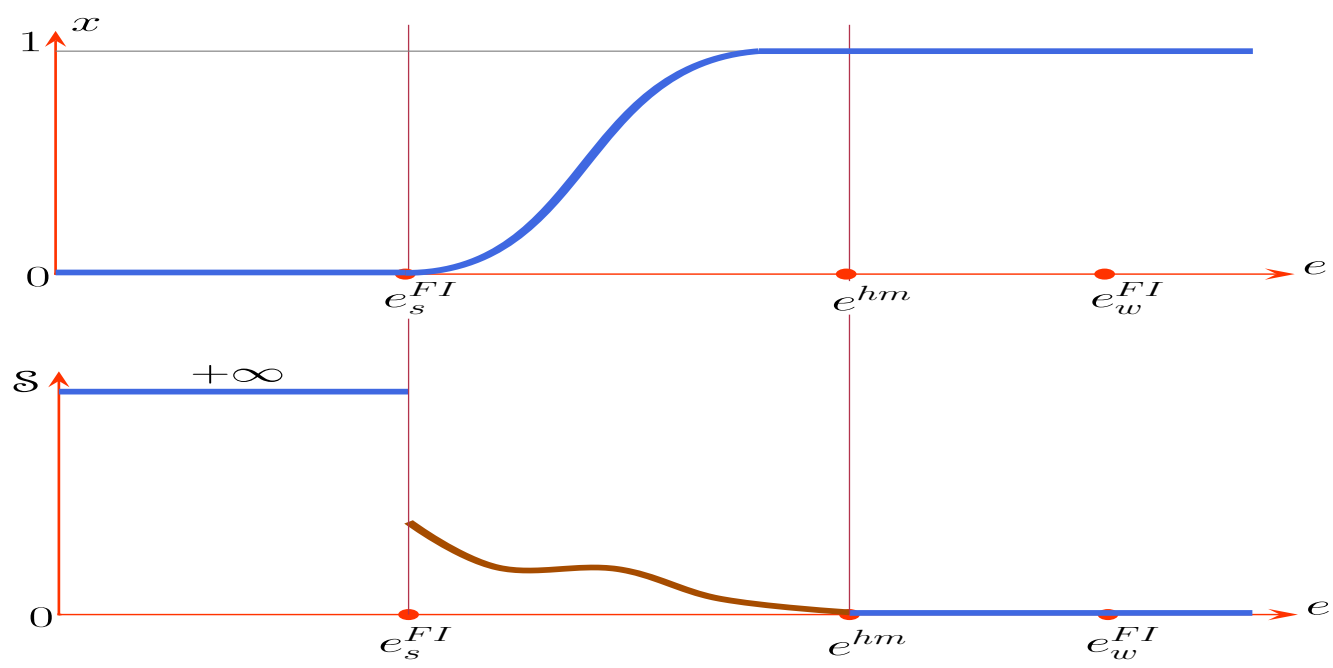

Figure 3b: Equilibrium with Unlimited Short Sales (SS)

We now examine some comparative statics, focusing on the relevant range for analysis $e \in\left[e_{s}^{F I}, e^{h m}\right] \cdot{ }^{20}$

Proposition 3: For a given peg e, an increase in the demand for foreign borrowing (an ${ }^{20}$ For $e>e^{h m}$, the outcome is the same as for $e=e^{h m}$. 
increase in $\alpha$ ) in the government's objective function leads to

- an increase in speculative activity

- a depreciation of the currency of the weak type

- if speculative activities are SS (SC), an increase (decrease) in the probability of maintaining the peg.

Intuitively, as the government is more concerned about investment, it becomes more willing to sacrifice purchasing power of consumers to attract investment. At a given peg, this occurs through an increase in speculative activities, and, under SS, a higher probability of maintaining the peg.

The same proposition also holds when the marginal productivity of investment $\left(\frac{\partial \pi}{\partial I}\right)$ increases independently of $\alpha$.

Adding an export sector: We can also consider a version of the model where there is a export sector with little political weight, so that the government is still in favor of a strong currency. For instance, suppose the government's objective function is:

$$
\pi(I, \alpha)+\hat{\pi}(\hat{I}, \hat{\alpha})+v\left(e_{2}\right)
$$

where $\hat{I}$, the non-tradable investment in the export sector, is increasing in $f, \hat{\alpha}$ is increasing with the weight on the export sector and $\partial \hat{\pi} / \partial \hat{I}>0$ and $\partial^{2} \hat{\pi} / \partial \hat{\alpha} \partial \hat{I}>0$. The foreign exchange market clears as:

$$
\mathcal{R}_{i}-\frac{\mathcal{S}}{e}-\frac{D-\mathcal{S}}{e_{i}}=c_{2}^{*}\left(e_{i}\right)+\frac{r}{e_{i}} I+\hat{r} \hat{I} .
$$

We also have the same result as in the proposition above when we decrease the weight put on the export sector in the government's objective function.

The comparative statics above have counterparts in empirical studies. Blomberg, Frieden and Stein (2003) investigate fixed exchange rates in Latin America and find that the larger the tradables sector exposed to international competition, the larger the probability of devaluation. Frieden (1994) interprets American exchange-rate policy in terms of special interests. He argues that the dollar devaluation in the 1890s was supported by farmers and other producers of traded goods who faced commodity price shocks. In 1933, devaluation, he argues, was favored by farmers, silver miners, and other producers of traded goods whose prices had collapsed immediately after the stock market crash of 1929, but was strongly opposed by the service sector. 


\subsection{Choice of peg}

The peg $e$ could result from legacy arrangements and have not been adjusted to reflect country shocks that occurred before date 1 of the model. For example, the Argentinian peso-dollar parity peg had become too ambitious in the late 90 's after a series of negative shocks but was not readjusted; or the adjustments of parities within the former European Monetary System required lengthy negotiations and therefore often occurred with substantial lag. The analysis then stops here and indicates the strength of the speculative attack and the government reaction for this legacy peg. Alternatively, and this is the case considered in our timing, the choice of peg is selected at date 1 .

In perfect Bayesian equilibrium, the peg is effectively dictated by the strong type's preferences. The welfare of the strong type as a function of $e$ is:

$$
W_{s}=\pi(I(f), \alpha)+v\left(e_{s}\right) .
$$

Note first that the strong type can guarantee itself $W_{s}^{F I}$ by setting $e=e_{s}^{F I}$.

In the relevant range $e \in\left[e_{s}^{F I}, e^{h m}\right]$, so the equilibrium defines a feasible set $\left\{e, e_{s}(e)\right\}$. The strong type solves:

$$
\max _{e}\left\{\pi(I(e), \alpha)+v\left(e_{s}(e)\right)\right\}
$$

Setting an exchange rate $e$ between $e_{s}^{F I}$ and $e^{h m}$ involves a trade-off: on the one hand, investment falls from $I\left(e_{s}^{F I}\right)$ to $I(e)$, reducing corporate welfare; on the other hand, the strong type makes money on speculators, increasing future purchasing power of the consumers. Intuitively, the former effects receives more attention as $\alpha$ increases:

Proposition 4: As a increases, the equilibrium peg $e^{*}$ (weakly) decreases (the peg becomes more ambitious). ${ }^{21}$

Special case 1: For a simple case where the optimal announced exchange rate $e^{*}>e_{s}^{F I}$ and there is a crisis $(x \in(0,1))$, consider the corporate finance example described in Section 3 and the following parametrization of production $R(I)$ with constant returns to scale up to an investment upper capacity $\bar{I}$ :

$$
R(I)=\min \{R I, R \bar{I}\},
$$

for some $R$ sufficiently large that entrepreneurs want to invest as much as they can and $I\left(e_{s}^{F I}\right)>\bar{I}>I\left(e^{h m}\right)$. Define $e^{*}>e_{s}^{F I}$ such that $\bar{I}=I\left(e^{*}\right)$. Intuitively, decreasing returns

\footnotetext{
${ }^{21}$ This proposition applies to the equilibrium sets if there are multiple equilibria: If $e_{1}^{*}$ is optimal for $\alpha_{1}$ and $e_{2}^{*}$ is optimal for $\alpha_{2}<\alpha_{1}$, then $e_{1}^{*} \leq e_{2}^{*}$.
} 
in the benefits of foreign borrowing dampen the strong type's incentive to separate:

Proposition 5: In the corporate finance example, when $R(I)=\min \{R I, R \bar{I}\}$, the equilibrium peg exceeds the full information optimum for the strong type $\left(e^{*}>e_{s}^{F I}\right)$.

Special case 2 (log utility): Suppose the utility function is:

$$
u\left(c_{2}^{*}\right)=\log \left(c_{2}^{*}\right) .
$$

We have observed that the sorting condition holds in this case.

Proposition 6: With log utility, the weak type's equilibrium probability of defending the exchange rate, $x(e)$, is non-decreasing in the announced exchange rate $e$.

For log utility, it can be easily shown that the strong type chooses to separate (chooses $e=e_{s}^{F I}$ ) if and only if $\frac{\mathfrak{s}}{e}$ is maximized at $e=e_{s}^{F I}$ over $\left[e_{s}^{F I}, e^{h m}\right]$. While we have been unable to prove analytically that this condition holds, it was satisfied in numerous simulations.

\section{No Short Sales}

\subsection{Speculative attack and response for a given peg}

Suppose now that speculation is bounded above by the short-term debt $D$ in pesos. The equilibrium identified above is still an equilibrium as long as

$$
\mathcal{S} \leq D
$$

In particular, when $e \geq e^{h m}$, the previous equilibrium had no speculative attack and therefore is not altered by the no-short-sales constraint. When $e<e_{s}^{F I}$, then $\mathcal{S}=D$ : speculation is repressed by the constraint on short sales.

Focusing, last, on the interesting region, $e_{s}^{F I} \leq e<e^{h m}$, suppose to the contrary, that in the equilibrium analyzed in Section 4, speculation involves short sales. Because $\mathcal{S}=0$ and/or $x=0$ cannot be part of an equilibrium (by the same reasoning as in the Short Sales section), we have

$$
\frac{1}{e} \geq \frac{1}{f}=\frac{\rho^{\prime}}{e_{s}}+\frac{1-\rho^{\prime}}{e_{w}}
$$

and

$$
W_{w}^{F I} \leq \pi(I(f), \alpha)+v\left(e_{w}\right)
$$


Furthermore,

$$
\mathcal{R}_{i}-\frac{\mathcal{S}}{e}-\frac{D-\mathcal{S}}{e_{i}}=c_{2}^{*}\left(e_{i}\right)+\frac{r}{e_{i}} I(f) \quad i \in\{w, s\}
$$

Consider, first, the possibility of non-repressed speculation $(f=e)$. Then $\mathcal{S} \leq D$ would be an equilibrium of the short-sales situation with $x \leq 1$ and $W_{w}^{F I}=\pi(I(f), \alpha)+v\left(e_{w}\right)$ or $x=1$ and $W_{w}^{F I}<\pi(I(f), \alpha)+v\left(e_{w}\right)$, a contradiction. Thus the equilibrium without short-sales involves repressed speculation:

$$
f>e,
$$

and so $\mathcal{S}=D$ and $I(f)<I(e)$ : short-sale constraints reduce the capital inflow conditional on the peg being maintained.

The forward rate $f$, the date- 2 exchange rates $e_{s}$ and $e_{w}$, and the pooling probability are then given by the following system of equations:

$$
\begin{gathered}
\mathcal{R}_{w}-\frac{D}{e}=c_{2}^{*}\left(e_{w}\right)+\frac{r}{e_{w}} I(f), \\
W_{w}^{F I} \geq \pi(I(f), \alpha)+v\left(e_{w}\right), \quad \text { with equality if } x<1, \\
\mathcal{R}_{s}-\frac{D}{e}=c_{2}^{*}\left(e_{s}\right)+\frac{r}{e_{s}} I(f),
\end{gathered}
$$

and

$$
\frac{1}{f}=\frac{\rho^{\prime}(x)}{e_{s}}+\frac{1-\rho^{\prime}(x)}{e_{w}} .
$$

Next, note that the facts that $I(f)<I(e)$ and that $\mathcal{S}$ is smaller than under short sales (short sales constraints cut the weak type's losses) imply that $e_{w}$ appreciates relative to the short-sales case.

Proposition 7. (When they are binding), short sales constraints:

- reduce the capital inflow when the peg is maintained

- appreciate the weak type date-2 exchange rate when the peg is maintained

- raise the probability that the weak type defends the peg when $e_{s}$ is fixed. 


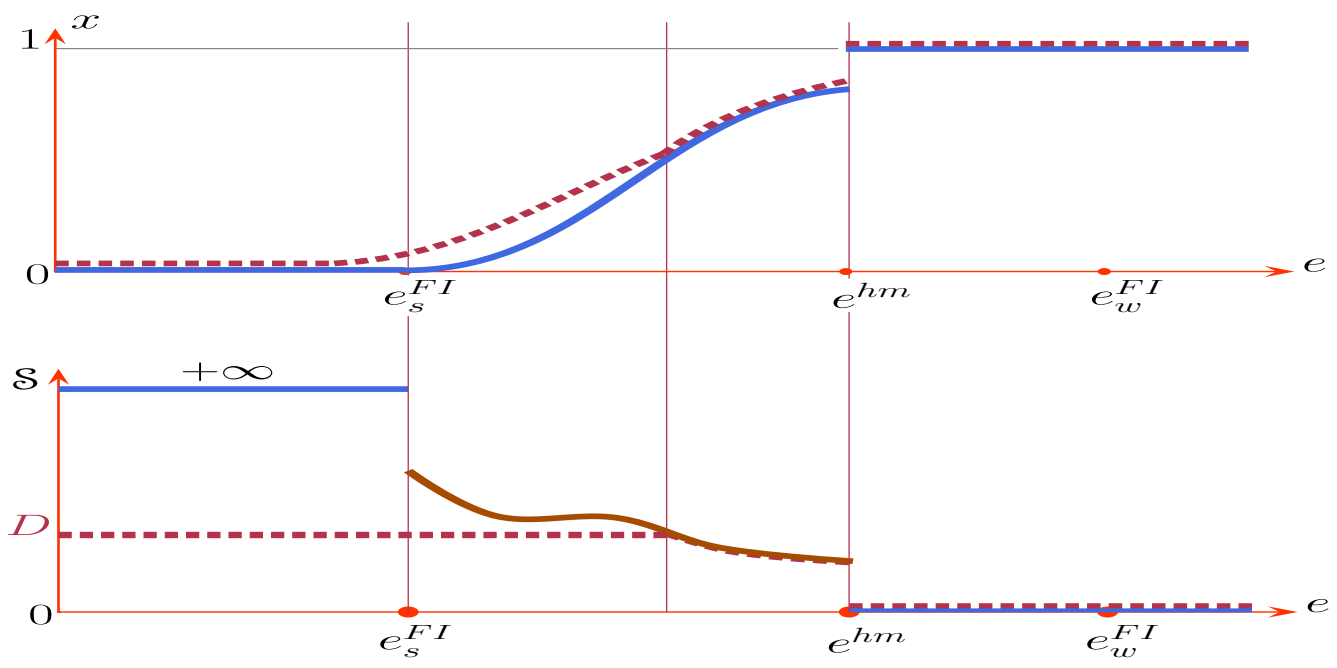

Figure 4.- Equilibrium with No Short Sales (SC).

\section{$5.2 \quad$ Choice of peg}

We investigate the choice of peg in a structured example.

Example: Existence of a fundamental exchange rate

Let us specialize the model by assuming that, regardless of the type, the country has a fundamental exchange rate. This assumption is in line with much of the literature on speculative attacks, in particular Morris and Shin (1998). To obtain fundamental exchange rates, 1 and $e_{w}>1$ respectively, let us assume that

$$
u\left(c_{2}^{*}\right)=\left\{\begin{array}{l}
e_{w} c_{2}^{*} \quad \text { for } c_{2}^{*} \leq c_{0}^{*} \\
e_{w} c_{0}^{*}+\left(c_{2}^{*}-c_{0}^{*}\right) \quad \text { for } c_{2}^{*}>c_{0}^{*}
\end{array}\right.
$$

and that $\mathcal{R}_{s}$ is large enough and $\mathcal{R}_{w}$ small enough that the strong and weak types' exchange rates are always 1 and $e_{w}$, respectively in the relevant range.

With fundamental exchange rates, speculative activities are weak complements or substitutes according to Definition 1 as $\frac{1}{f}=\rho+\frac{(1-\rho)}{e_{w}}$ is invariant for a given $\rho$. In the presence of short sales, as $e$ increases from 1 to $e^{h m}, \mathcal{S}$ decreases continuously to 0 and $x$ increases continuously from 0 to 1 . 
We use the example in Section 2, with the specifications $R(i)=R i$ (linear technology) and $\alpha=1$ (the government puts equal weight on both constituencies). Let us introduce two exchange rates, $e^{-}$and $\underline{e}$. Define $e^{-}$to satisfy:

$$
I(1)-I\left(e_{w}\right)=\frac{D}{R-r}\left(\frac{e_{w}}{e^{-}}-1\right)
$$

(note that $e^{-}$goes to 0 as $D$ goes to 0 ). It can be shown that $e^{-}<1$ if the no-short sale constraint is ever binding. Let us further assume that the exchange rate cannot fall below some level $\underline{e}<1$; for example, there is a technology that transforms $\frac{1}{e}$ units of tradables into 1 unit of non-tradables. For instance, US real estate, which is normally non-tradable by and large, becomes tradable if the dollar becomes too weak as foreigners buy secondary residences there.

Proposition 8. In the corporate finance example, with $R(i)=R i$ and $\alpha=1$, and under a fundamental exchange rate (1 for the strong type, $e_{w}>1$ for the weak type), and without short sales, the equilibrium peg is $\max \left(e^{-}, \underline{e}\right)$. If this value is $e^{-}$, the strong type separates. Otherwise, there is some pooling by the weak type (and therefore financial crises).

\section{$6 \quad$ Hedging}

In our model, domestic residents are "risk neutral," but there are gains from trade when there is some pooling: they could promise to deliver dollars when the realized exchange rate is low and receive dollars when the realized exchange rate is high. Suppose that the exchange rate will appreciate to $e_{s}$ with probability $\rho^{\prime}$ and depreciate to $e_{w}$ with probability $1-\rho^{\prime}$. Domestic residents can obtain a basic insurance contract with international lenders (domestic financial intermediaries can do the hedging or exchange rate stabilization on their behalf) that will pay them $\frac{1}{1-\rho^{\prime}}$ units of tradables in case of depreciation and pays the $\frac{1}{\rho^{\prime}}$ units of tradables if the currency appreciates. Foreigners break even on such basic insurance contracts, and residents receive a gain in expected utility equal to

$$
\rho^{\prime}\left(-\frac{1}{\rho^{\prime}}\right) e_{s}+\left(1-\rho^{\prime}\right)\left(\frac{1}{1-\rho^{\prime}}\right) e_{w}=e_{w}-e_{s}>0
$$

More generally, trades in such contracts will eliminate exchange rate uncertainty.

Entering FX insurance contracts is usually prohibitively costly for individuals; larger entities, e.g. financial institutions, can hedge FX risk, though. In practice, a government can limit hedging in many ways. ${ }^{22}$ For example, it could not enforce risk management policies

\footnotetext{
${ }^{22}$ Reinhart et al. (2003) highlight the endogenous character of domestic dollarization empirically. They point
} 
of banks supervised by the banking commission; this policy encourages FX risk exposure if banks face a soft budget constraint and expect to be bailed out in times of crises. Another simple policy to limit hedging is to subsidize offshore borrowing. ${ }^{23}$ We capture this policy dimension in our model by allowing the government to cap the number of basic insurance contracts.

The prospect of hedging by domestic residents increases the weak type's incentive to maintain the peg and makes it more costly for the strong type to separate. We consider the following extension to our game, in which the government can also either allow or limit hedging. Namely, enrich the timing in the following way:

- At stage (d), the speculators take $\mathcal{S}$ out of the country. The government observes $\mathcal{S}$ and simultaneously chooses (i) whether to defend the peg or let the currency float and (ii) a maximum volume $V$ of the basic insurance contracts described above that domestic residents can enter into.

- At stage (e), domestic entrepreneurs finance equipment in tradables by borrowing abroad. Domestic residents enter into $v \in[0, V]$ basic insurance contracts with foreigners. $^{24}$

The rest of the timing is unchanged.

The exchange rate determination is as earlier, except that reserves $\mathcal{R}_{i}$ must be replaced by $\hat{\mathcal{R}}_{i}$ where

$$
\hat{\mathcal{R}}_{s} \equiv \mathcal{R}_{s}-\frac{v}{\rho^{\prime}}
$$

and

$$
\hat{\mathcal{R}}_{w} \equiv \mathcal{R}_{w}+\frac{v}{1-\rho^{\prime}},
$$

where, as earlier, $\rho^{\prime}$ denotes the posterior belief at stage (e). For example, when maintaining

out that governments, in dealing with macroeconomic instability which is of course endogenous, may facilitate residents' holding of financial assets indexed to a foreign currency or to some other stable unit of account.

${ }^{23}$ For example, some commentators have argued that the Bangkok International Banking Facility, initially established to intermediate foreign investment, functioned as a conduit for short-term foreign lending. Thailand also famously offered tax breaks which encouraged offshore borrowing.

${ }^{24}$ For example, the government can impose tax rate $\tau$ on receipts from such contracts. Then the actual volume is controlled by the tax rate:

$$
\begin{array}{r}
\text { either } e_{s}=e_{w}(1-\tau) \text { and } v \geq 0 \\
\text { or } e_{s}>e_{w}(1-\tau) \text { and } v=0 .
\end{array}
$$


the peg, $e_{i}$ is given by:

$$
\hat{\mathcal{R}}_{i}-\frac{\mathcal{S}}{e}-\frac{D-\mathcal{S}}{e_{i}}=c_{2}^{*}\left(e_{i}\right)+\frac{r}{e_{i}} I(f) .
$$

With this extension to our framework, the strong type wants to prohibit hedging by residents for two reasons:

- Under pooling, the currency is undervalued, so hedging is disadvantageous.

- The strong type (who loses when residents hedge) wants to separate from the weak type (who gains when residents hedge).

When the strong type prohibits hedging, the weak type is forced to mimic and with this extension we return to the equilibrium described above.

We can summarize this discussion in the following proposition.

Proposition 9: In the extended game in which the government chooses the extent to which the domestic residents can hedge, the equilibrium obtained when residents cannot hedge is still an equilibrium. Indeed:

- either the government maintains the peg and then fully prohibits hedging: $V=0$ (this happens with probability $\rho+(1-\rho) x(e)$ if the peg is e)

- or the government abandons the peg in which case there is no hedging either.

The proof of Proposition 9 is straightforward. For $e \geq e_{s}^{F I}$, let the market believe that the government has a weak type $\left(\rho^{\prime}=0\right)$, if it either abandons the peg or allows any hedging $(V>0)$. For $e<e_{s}^{F I}$, the market believes that the government has the weak type if it allows any hedging. Then, no hedging takes place regardless of the government's behavior at stage (d). So the outcome and payoffs are the same as in Section 4 (with unlimited short sales) or Section 5 (no short sales).

Needless to say, the conclusion that there is never any hedging, while striking, is extreme. For example, introducing external shocks would make it costly for domestic firms with ongoing projects not to hedge FX risk. ${ }^{25}$ In those more general environments, the government would allow some hedging, but the general conclusion would remain: Policies encouraging hedging do signal weak fundamentals. ${ }^{26}$

\footnotetext{
${ }^{25}$ As in Holmström and Tirole (2000) for example.

${ }^{26}$ Prior to the Mexican crisis, a substantial portion of the public debt was restructured from cetes (pesodenominated) to tesobonos (dollar-denominated). Pedro Aspe, then finance minister, said that the tesobonos were the government's "self-binding commitment to fulfill the intended discipline in public finance" (quoted in Kessler (2000)). By ensuring that a devaluation would increase the public debt, the creation and rapid growth of this financial instrument signaled to foreign investors that the government was not going to allow the currency to fall.
} 


\section{Short-term Liabilities as an Escape Option}

Our model assumed that the peso liabilities (debt, equity portfolio, etc.) were short-term in that the foreign investors could avail themselves of the money at date 1. More generally, we could decompose peso liabilities into short-term (due at date 1) and long-term (due at date 2) liabilities:

$$
D=D^{S T}+D^{L T} .
$$

It is often argued that foreign investors demand short-term debt (when in local currency) so as to be able to "escape on time." While intuitive, this argument requires some deepening: After all, foreigners would derive no benefit for a short maturity if exchange rates followed a martingale. This is indeed what happens in the case of short sales, for which

$$
\frac{1}{e}=\frac{1}{f}=E\left[\frac{1}{e_{2}}\right]
$$

The maturity choice is then neutral: all equilibrium variables, including exchange rates, given by:

$$
\mathcal{R}_{i}-\frac{\mathcal{S}}{e}-\frac{D^{S T}+D^{L T}-\mathcal{S}}{e_{i}}=c_{2}^{*}\left(e_{i}\right)+\frac{r}{e_{i}} I(e)
$$

are invariant to a chance in the maturity structure, keeping $D$ constant.

By contrast, the absence of short sales, when it is binding, breaks down the martingale property:

$$
\frac{1}{e}>E\left(\frac{1}{e_{2}}\right)
$$

as was shown in section 5 . To the extent that $\mathcal{S} \leq D^{S T}$, domestic borrowers have an incentive to tilt the maturity structure of their liabilities toward the short end:

$$
D^{S T}=D
$$

Another interesting point is that the government has no incentive to oppose this shortterm bias, for a now-familiar reason: The weak type would rather have these liabilities converted at the unfavorable rate $e_{w}$ at date 2 than at the better rate $e$ at date 1 ; but forcing the domestic borrowers to borrow long is an open admission of a future depreciation.

This discussion can be summarized in the following proposition.

Proposition 10: The maturity structure of liabilities

(i) is neutral under costless short sales; 
(ii) is not neutral in the absence of short sales. Domestic borrowers prefer to offer short term liabilities as the exchange rate does not follow a martingale; the government cannot tilt the maturity structure of these liabilities without confessing a future depreciation.

\section{Signaling Competency to Domestic Voters}

Consider the second illustration alluded to in the introduction where the third parties are domestic voters who are more likely to re-elect the government if the latter's past management is associated with strong fundamentals. Unlike the first example, this model contains no corporate sector and no capital inflow motive for maintaining the peg.

Let the welfare of the government be

$$
W=\alpha \phi\left(\rho^{\prime}\right)+v\left(e_{2}\right)
$$

where $\phi(\cdot)$ is an increasing function, so the government values appearing as a strong type. The parameter $\alpha$ governs the government's desire to be seen as strong, so $\alpha$ may be high in the months preceding an election and fall after the government is re-elected, and is equal to zero or may even be negative if a new government takes over (as the latter benefits from the electorate viewing the predecessor as incompetent).

Without entrepreneurs in the model, there is no investment and the foreign exchange market clearing equation is:

$$
\mathcal{R}_{i}-\frac{\mathcal{S} y_{i}}{e}-\frac{D-\mathcal{S} y_{i}}{e_{i}}=c_{2}^{*}\left(e_{i}\right), \quad \text { for } i \in\{w, s\} .
$$

An addendum to this paper, ${ }^{27}$ Pathak and Tirole (2004), shows that the key results of the first illustration carry over to the second illustration. In particular, when the government's re-election motive increases, there will be an increase in speculative activity and if speculative activities are SS, an increase in the probability of maintaining the peg (Proposition 3). Furthermore, with binding short sales constraints the weak type receives partial impunity from speculative attacks as before; therefore it has more incentives to defend the peg (Proposition 7). Finally, government's policies serve as a cluster of signals: when the government can influence the extent of hedging in the economy, it will discourage hedging in equilibrium; and it does not encourage firms to lengthen the maturity structure of their

\footnotetext{
${ }^{27}$ Available from the author's webpages or upon request.
} 
liabilities because doing so would confess a future depreciation (Propositions 9 and 10).

Proposition 11: When the government wants to signal competency to domestic voters $\left(W=\alpha \phi\left(\rho^{\prime}\right)+v\left(e_{2}\right)\right.$ with $\left.\phi^{\prime}>0 ; \mathcal{R}_{i}-\frac{\mathcal{S}}{e}-\frac{D-\mathcal{S}}{e_{i}}=c_{2}^{*}\left(e_{i}\right)\right)$,

(i) the sorting condition (Assumption 2) is automatically satisfied, and there is no counterpart to Assumption 1 (electoral concerns mechanical create a demand for a reputation for strong fundamentals);

(ii) Proposition 1 through 10 (exception for Propositions 5 and 8, which are now irrelevant) still hold.

The second illustration formalizes the conventional wisdom that policymakers may be reluctant to devalue because they wish to be associated with strong fundamentals. ${ }^{28}$ Numerous cross-sectional studies have documented that devaluations are less likely shortly before elections, but often occur right after an election when a new government can blame the previous government for mismanagement. For example, in a sample of Latin American countries, Blomberg et al. (2003) find that when an election approaches, pegs are more likely to be maintained. Specifically, when an election is impending, the conditional likelihood of staying on a peg increases by roughly 8 percent. After the election the probability of devaluation increases by 4 percent. Klein and Marion (1997) also show, for a different sample of 17 Latin American countries, that a peg is more likely to be abandoned right after a change in the executive.

\section{Conclusion}

This paper's purpose has been to develop a simple micro-founded model of pegs and currency crises. Its basic point is that a country may adhere to a fixed exchange rate regime in order to signal strong fundamentals and thereby either facilitate the corporate sector's access to international borrowing or increase the government's chances of re-election; and that policy decisions come as a package: Signaling strong fundamentals requires not only setting and defending an ambitious peg, but also discouraging (or at least not encouraging) country hedging, allowing for short maturity structures, and so forth. Some of the results, namely country exposure to FX risk and to short-term debt have counterparts in a moral hazard context in which the government may exert insufficient care to protect the value of foreign holdings of domestic assets and therefore tries to commit by encouraging, or at least, letting

\footnotetext{
${ }^{28}$ Former Mexican President José López Portillo famously said "the president who devalues is devalued," quoted in Kessler (2000).
} 
the corporate sector engage in original sin. ${ }^{29}$ The welfare implications, though, are quite different: In our adverse selection setting, the fixed exchange rate and the lack of hedging may immiserize the country and leave rents to foreign speculators.

The introduction already summarized the main insights. Let us rather discuss some of the (many) areas for future research. It will be clear to the reader that our model is overly simplistic and should be enriched in several directions:

(1) Comparison of alternative FX support strategies: We have assumed that the country defends the currency by letting reserves deccumulate. Alternatively, it could raise interest rates. ${ }^{30}$ As Drazen (2001) and Drazen and Hubrich (2003) point out, however, an interest rate defense is costly to both the government and the corporate sector, and may actually signal weak fundamentals.

Furthermore, the country might not enter a peg and yet still signal by managing the float. To accommodate this possibility within the context of our model, one can assume that at stage (c), the government, rather than pegging, offers to buy $B$ pesos (in exchange for a market-determined amount of dollars). At stage (d), the FX market, having observed $B,{ }^{31}$ updates its beliefs about the fundamentals (a higher $B$ signaling a higher confidence in the fundamentals), and clears at the foreign exchange rate $f .{ }^{32}$

(2) External shocks and choice of exchange rate regime: External shocks (to terms of trade, say) could be added to the model. Provided that the peg is not adjusted perfectly to reflect such shocks, the question arises of how alternative exchange rate regimes accommodate the shocks. One could revisit the large literature on exchange rate regimes from this perspective.

(3) Dynamics: Our model lacks dynamics in several respects. First, the speculative attack and the decision of defending the peg are one-shot. Our model can be extended to depict the game between speculators and governments as a war of attrition. Second,

\footnotetext{
${ }^{29}$ See Tirole (2003), where it is further argued that foreign debt holding and home biases also discipline the government.

${ }^{30}$ To accommodate this possibility within the context of our model, one could assume that at stage (c) the government further sets a peso interest rate $\nu>0$. This policy engenders a windfall gain for foreign investors, whose peso asset value jumps from $D$ to $(1+\nu) D$. It further reduces the peso NPV of production by entrepreneurs.

${ }^{31}$ Assuming $B$ is observed; alternatively, $B$ could be observed imperfectly due to noise trading, as in the market microstructure literature.

${ }^{32}$ The date- 2 exchange rate is then given by:
}

$$
\mathcal{R}_{i}-\frac{B}{f}-\frac{D-B}{e_{i}}=c_{2}^{*}\left(e_{i}\right)+\frac{r}{e_{i}} I(f), \quad \text { for } i \in\{w, s\}
$$


the dynamics of investment would be better described in an infinite-horizon model. The sharp decline in investment when the peg is abandoned in our model has a crosssectional nature. Its time-series counterpart in an emerging economy would be similar, but better correspond to the evidence on sudden stops.

(4) Political economy: Our political economy approach has treated the government as a unitary actor. Often, the central bank is responsible for exchange rate management, and policies that affect the costs of hedging are the responsibility of other sectors of government, such as banking regulators. Exploring the consequences of the interaction between these different agents is an another direction for future work.

(5) Demand for weak currency: While our model has emphasized the demand for a strong currency (Assumption 1), a country may want a weak currency to be competitive in export markets. The model developed in this paper could be employed to study the incentives of a government favoring exporters' interests to buy dollars. Because this policy succeeds in depreciating the local currency only if markets cannot tell weak and strong fundamentals apart, we conjecture that competitive depreciations should be accompanied by the government's encouraging hedging, even though a high level of hedging is not in the country's direct interest when fundamentals are strong.

(6) Propagation of speculative attacks: Competitive devaluations (as opposed to competitive depreciations) occur when countries have a demand for a strong currency. Recent crises have shown that one of the mechanisms of international propagation of currency crises is through trade effects. In a two-country model, where speculators sequentially mount their attacks, a depreciation in one country may trigger a stronger speculative attack and a depreciation in the other country through a competitive devaluation effect. We plan to analyze this situation in more depth in future work.

(7) Nominal exchange rate: Because micro-founded models of the nominal exchange rate are notoriously hard to develop, we have focused on real exchange rates for simplicity. It goes without saying that the analysis of nominal exchange rates stands high on the research agenda.

We leave these, and other important extensions for future research. 


\section{Appendix}

Proof of Proposition 1. The market clearing equations for $i \in\{w, s\}$

$$
\mathcal{R}_{i}-\frac{\mathcal{S}}{e}-\frac{D-\mathcal{S}}{e_{i}}=c_{2}^{*}\left(e_{i}\right)+\frac{r}{e_{i}} I(f)
$$

imply that $e_{s}<e_{w}$. This is obviously true if $\mathcal{S} \leq D$. More generally, consider the lowest $\mathcal{S}$ such that $e_{w}=e_{s}$; the two market clearing conditions are then inconsistent, which shows that there can be no such $\mathcal{S}$.

Next, let

$$
\frac{1}{f}=\frac{\rho^{\prime}}{e_{s}}+\frac{1-\rho^{\prime}}{e_{w}}
$$

Assume first that $e_{w} \leq e_{w}^{F I}$. Then $f<e_{w}^{F I}$; for, if $f=e_{w}^{F I}$ then $\rho^{\prime}=0$ and $e_{w}=e_{w}^{F I}$, which implies that $\mathcal{S}=0$. But $\mathcal{S}=0$ is not optimal for speculators as $e<f$.

Because $f<e_{w}^{F I}, I(f)>I\left(e_{w}^{F I}\right)$, and the RHS of the exchange rate clearing equation for the weak type strictly exceeds its full information level. This in turn requires that the same be true for the LHS:

$$
\frac{\mathcal{S}}{e}+\frac{D-\mathcal{S}}{e_{w}}<\frac{D}{e_{w}^{F I}}
$$

which in turn can hold only if $\mathcal{S}>0$ and $e_{w}<e$, which itself would imply $f<e$ and so $\mathcal{S}=0$, a contradiction. The proof that $e_{s}<e_{s}^{F I}$ is identical, by symmetry.

Proof of Proposition 2. Let us demonstrate this proposition for $\rho$ small. Differentiating (5) yields:

$$
\frac{d e_{w}}{d \mathcal{S}}\left[c_{2}^{*^{\prime}}-\frac{r}{e_{w}^{2}} I-\frac{D-\mathcal{S}}{e_{w}^{2}}\right]=\frac{1}{e_{w}}-\frac{1}{e}-\frac{r}{e_{w}} I^{\prime} \frac{d f_{\rho}}{d \mathcal{S}},
$$

where $\frac{d f_{\rho}}{d \mathcal{S}} \approx \frac{d e_{w}}{d \mathcal{S}}$ for $\rho$ small. Therefore,

$$
\frac{d e_{w}}{d \mathcal{S}}\left[c_{2}^{*^{\prime}}-\frac{r}{e_{w}^{2}} I-\frac{D-\mathcal{S}}{e_{w}^{2}}+\frac{r}{e_{w}} I^{\prime}\right] \approx \frac{1}{e_{w}}-\frac{1}{e} .
$$

From Proposition 1, the RHS is negative and bounded away from 0. Because $I^{\prime}<0$, the coefficient of $\frac{d e_{w}}{d \mathcal{S}}$ is negative for $\mathcal{S} \leq D$. The coefficient must actually remain negative, otherwise $e_{w}$ would go to infinity for some $\mathcal{S}$. Hence,

$$
\frac{d e_{w}}{d \mathcal{S}} \geq k>0, \quad \text { for some } k .
$$


Thus the forward rate increases with $\mathcal{S}$ for $\rho$ small. The proof of SS for $\rho$ large follows a similar reasoning.

Proof of Proposition 3. Recall that $f=e$ when the peg is defended. Either $W_{w}^{F I}<$ $\pi(I(e), \alpha)+v\left(e_{w}\right)$ and then nothing changes $(x=1)$ or $W_{w}^{F I}=\pi(I(e), \alpha)+v\left(e_{w}\right)$. Because $I(e)>I_{w}^{F I}$ and $\frac{\partial^{2} \pi}{\partial I \partial \alpha}>0, e_{w}$ must increase to keep the equality satisfied. Thus the weak type must lose more money on the FX market:

$$
\mathcal{R}_{w}-\frac{\mathcal{S}}{e}-\frac{D-\mathcal{S}}{e_{w}}=c_{2}^{*}\left(e_{w}\right)+\frac{r}{e_{w}} I(e),
$$

and so $\mathcal{S}$ increases. Last, an increase in $\mathcal{S}$ under SS (according to Definition 1 ) raises $\frac{1}{f}$ for a given $x$. So $x$ must increase in order to re-establish the speculators' zero-profit condition. $\diamond$

Proof of Proposition 4. This follows from a simple revealed preference argument: let $e_{1}^{*}$ be an optimal peg for $\alpha_{1}$ and let $e_{2}^{*}$ be an optimal peg for $\alpha_{2}$, where $\alpha_{1}>\alpha_{2}$ :

$$
\begin{aligned}
& \pi\left(I\left(e_{1}^{*}\right), \alpha_{1}\right)+v\left(e_{s}\left(e_{1}^{*}\right)\right) \geq \pi\left(I\left(e_{2}^{*}\right), \alpha_{1}\right)+v\left(e_{s}\left(e_{2}^{*}\right)\right) \\
& \pi\left(I\left(e_{2}^{*}\right), \alpha_{2}\right)+v\left(e_{s}\left(e_{2}^{*}\right)\right) \geq \pi\left(I\left(e_{1}^{*}\right), \alpha_{2}\right)+v\left(e_{s}\left(e_{1}^{*}\right)\right)
\end{aligned}
$$

Subtracting the RHS of the second equation from the LHS of the first equation and the LHS of the second equation from the RHS of the first equation and taking the limit as $\alpha_{2} \rightarrow \alpha_{1}$ we obtain:

$$
\frac{\partial \pi\left(I\left(e_{1}^{*}\right), \alpha\right)}{\partial \alpha} \geq \frac{\partial \pi\left(I\left(e_{2}^{*}\right), \alpha\right)}{\partial \alpha}
$$

or $I\left(e_{1}^{*}\right) \geq I\left(e_{2}^{*}\right)$ since $\frac{\partial^{2} \pi}{\partial \alpha \partial I}>0$. Therefore, $e_{2}^{*} \geq e_{1}^{*}$, so the optimal peg becomes (weakly) more ambitious when $\alpha$ increases.

Proof of Proposition 5. For $e \leq e^{*}, I=\bar{I}$ and

$$
\begin{gathered}
\mathcal{R}_{i}-\frac{\mathcal{S}}{e}-\frac{D-\mathcal{S}}{e_{i}}=c_{2}^{*}\left(e_{i}\right)+\frac{r \bar{I}}{e_{i}} \\
W_{w}^{F I}=\pi(\bar{I}, \alpha)+v\left(e_{w}\right) .
\end{gathered}
$$

Therefore, $e_{w}$ is invariant on $\left[e_{s}^{F I}, e^{*}\right]$ and hence $\mathcal{S}\left(\frac{1}{e}-\frac{1}{e_{w}}\right)$ is invariant. We see that

$$
W_{s}=\pi(\bar{I}, \alpha)+v\left(e_{s}\right)
$$

increases if $e_{s}$ decreases. Using the weak type's FX clearing equation to substitute for $\mathcal{S}$, strong type FX clearing is: 


$$
\frac{D+r \bar{I}}{e_{s}}+c_{2}^{*}\left(e_{s}\right)=\mathcal{R}_{s}+\left(\frac{\frac{1}{e_{s}}-\frac{1}{e}}{\frac{1}{e}-\frac{1}{e_{w}}}\right)\left[\mathcal{R}_{w}-\frac{D+r \bar{I}}{e_{w}}-c_{2}^{*}\left(e_{w}\right)\right] .
$$

In a stable equilibrium (where "stability" refers to the Walrasian tatonnement process), $e_{s}$ decreases with $e$.

Proof of Proposition 6. FX clearing implies

$$
\frac{e_{s}}{e_{w}}=\frac{\mathcal{R}_{w}-\frac{s}{e}}{\mathcal{R}_{s}-\frac{s}{e}}
$$

which allows us to express the strong exchange rate $e_{s}$ in terms of $e$ :

$$
e_{s}=e\left[\rho^{\prime}(x)+\left(1-\rho^{\prime}(x)\right) \frac{\mathcal{R}_{w}-\frac{\delta}{e}}{\mathcal{R}_{s}-\frac{\mathcal{s}}{e}}\right] \text {. }
$$

Combining this with the strong-type FX clearing equation

$$
e_{s}=\frac{(D-\mathcal{S})+1+r I}{\mathcal{R}_{s}-\frac{\mathcal{S}}{e}},
$$

we find

$$
D+1+r I=e\left[\rho^{\prime}(x) \mathcal{R}_{s}+\left(1-\rho^{\prime}(x)\right) \mathcal{R}_{w}\right] .
$$

Since

$$
\frac{d \rho^{\prime}}{d e}=\frac{r I^{\prime}-\left(\rho^{\prime}(x) \mathcal{R}_{s}+\left(1-\rho^{\prime}(x)\right) \mathcal{R}_{w}\right)}{e\left(\mathcal{R}_{s}-\mathcal{R}_{w}\right)} \leq 0,
$$

we reach our desired conclusion $\frac{d x}{d e} \geq 0$.

Proof of Proposition 8. Without short sales, there exists some $e^{+}$in $\left(1, e^{h m}\right)$ such that the constraint $\mathcal{S} \leq D$ is binding exactly on $\left[1, e^{+}\right)$. We know the constraint must be binding for some $e^{+}>1$ since when $e=1, \mathcal{S}$ must satisfy:

$$
(R-r)\left[I(1)-I_{w}^{F I}\right]=\mathcal{S}\left(e_{w}-1\right),
$$

which implies that $\mathcal{S}>D$ for this value. We first show that the no-short-sales constraint $x$ remains increasing in $e$ to the left of $e^{+}$. Simple computations show that:

$$
W_{w}=(R-r) I-D \frac{e_{w}}{e}+e_{w} \mathcal{R}_{w}
$$

and

$$
W_{s}=(R-r) I-\frac{D}{e}+\mathcal{R}_{s},
$$


where $I$ is the investment corresponding to investment $e$ (as we have seen $I=I(f(e))<$ $I(e))$. Let us look for a mixed strategy with $x<1$ for the weak type and for $e<e^{+}$:

$$
W_{w}=(R-r) I-D \frac{e_{w}}{e}+e_{w} \mathcal{R}_{w}=(R-r) I_{w}^{F I}-D+e_{w} \mathcal{R}_{w} .
$$

As $e$ increases, $I$ must decrease to keep the weak type indifferent, and so $f$ must increase. Because

$$
\frac{1}{f}=\rho^{\prime}+\frac{1-\rho^{\prime}}{e_{w}}
$$

$x$ must increase with $e$.

The weak type no longer pools $(x=0)$ when $\rho^{\prime}=1$ (i.e. $f=1$ ). Thus, $x$ increases from 0 to 1 as $e$ goes from $e^{-}$to $e^{h m}$, where

$$
I(1)-I_{w}^{F I}=\frac{D}{R-r}\left(\frac{e_{w}}{e}-1\right) .
$$

The strong type's welfare is thus:

$$
W_{s}=W_{w}+\frac{e_{w}-1}{e} D+\mathcal{R}_{s}-e_{w} \mathcal{R}_{w}
$$

so $W_{s}$ is decreasing in $e$. The peg is therefore set at $\max \left(e^{-}, \underline{e}\right)$. 


\section{References}

Alesina, Alberto and Alexander Wagner, "Choosing (and Reneging on) Exchange Rate Regimes," 2003. Harvard University, mimeo.

Bartolini, Leonardo and Allan Drazen, "Capital Account Liberalization as a Signal," American Economic Review, 1997, 87, 138-154.

Blomberg, Brock, Jeffry Frieden, and Ernesto Stein, "Sustaining Fixed Rates: The Political Economy of Currency Pegs in Latin America," 2003. Harvard University, mimeo.

Bolton, Patrick and David Scharfstein, "A Theory of Predation Based on Agency Problems in Financial Contracting," American Economic Review, 1990, 80, 93-106.

Calvo, Guillermo A. and Carmen M. Reinhart, "When Capital Flows Come to a Sudden Stop: Consequences and Policy," in Peter Kenen and A. Swoboda, eds., Reforming the International Monetary and Financial System, International Monetary Fund, 2000. and ___ "Fear of Floating," Quarterly Journal of Economics, 2002, 117, 379-408.

Chamon, Marcos and Ricardo Hausmann, "Why Do Countries Borrow the Way They Borrow," 2002. Harvard University, mimeo.

Corrales, Javier, "Venezuela and the Shocks of 1997-98," in Carol Wise and Riordan Roett, eds., Exchange Rate Politics in Latin America, Brookings Institution Press, 2000.

Cukierman, Alex, Itay Goldstein, and Yossi Spiegel, "The Choice of Exchange Rate Regime and Speculative Attacks," 2004. Journal of the European Economic Association, forthcoming.

Drazen, Allan, "Interest Rate and Borrowing Defense Against Speculative Attacks," Carnegie-Rochester Conference Series on Public Policy, 2000, 53. , "Interest Rate Defense Against Speculative Attack as a Signal: A Primer," 2001. Tel Aviv, mimeo.

and Paul R. Masson, "Credibility of Policies Versus Credibility of Policymakers," Quarterly Journal of Economics, 1994, 109, 735-754.

and Stefan Hubrich, "Mixed Signals in Defending the Exchange Rate: What Do the Data Say?," 2003. Tel Aviv, mimeo.

Eichengreen, B., R. Hausmann, and U. Panizza, "Original Sin: The Pain, the Mystery, and the Road to Redemption," 2002. Harvard Kennedy School of Government, Unpublished mimeo. 
Eichengreen, Barry, "The Endogeneity of Exchange-Rate Regimes," in Peter Kenen, ed., Understanding Interdependence, Princeton University Press, 1995, pp. 3-33. and Ricardo Hausmann, "Exchange Rates and Financial Fragility," in "New Challenges for Monetary Policy," Federal Reserve Bank of Kansas City, 1999, pp. 329-368.

Fischer, Stanley, "Exchange Rate Regimes: Is the Bipolar View Correct?," Journal of Economic Perspectives, 2001, 15, 3-24.

Frieden, Jeffry, "Exchange Rate Politics: Contemporary Lessons from American History," Review of International Political Economy, 1994, 1, 81-103.

_ _ "The Politics of Exchange Rates," in "Mexico 1994: Anatomy of an Emerging-Market Crash," Washington: Carnegie Endowment for World Peace, 1997.

Ghosh, Atish, Anne-Marie Guide, and Holger Wolf, Exchange Rate Regimes: Choices and Consequences, MIT Press, 2003.

Giavazzi, Francesco and Marco Pagano, "The Advantage of Tying One's Hands: EMS Discipline and Central Bank Credibility," European Economic Review, 1988, 32, 10551082 .

Herrendorf, Berthold, "Transparency, Reputation, and Credibility Under Floating and Pegged Exchange Rates," Journal of International Economics, 1999, 49, 31-50.

Holmström, Bengt and Jean Tirole, "Liquidity and Risk Management," Journal of Money, Credit, and Banking, 2000, 32, 295-319.

Jeanne, Olivier, "Foreign Currency Debt and Signaling," 1999. International Monetary Fund, mimeo.

"Why Do Emerging Markets Borrow in Foreign Currency?," 2001. International Monetary Fund, mimeo.

and Andrew Rose, "Noise Trading and Exchange Rate Regime," Quarterly Journal of Economics, 2002.

Kessler, Timothy, "The Mexico Peso Crash: Causes, Consequences, and Comeback," in Carol Wise and Riordan Roett, eds., Exchange Rate Politics in Latin America, Brookings Institution Press, 2000.

Klein, Michael W. and Nancy P. Marion, "Explaining the Duration of Exchange-Rate Pegs," Journal of Development Economics, 1997, 97, 387-404.

Krugman, Paul, "A Model of Balance of Payments Crises," Journal of Money, Credit, and Banking, 1979, 11, 311-325. 
Levy-Yeyati, E., F. Sturzenegger, and I. Reggio, "On the Endogeneity of Exchange Rate Regimes," 2003. Universidad Torcuato Di Tella, mimeo.

McKinnon, Ronald and Huw Pill, "Credible Economic Liberalizations and Over-Borrowing," American Economic Review, 1997, 87, 189-93.

Morris, Stephen and Hyun Song Shin, "Unique Equilibrium in a Model of Self-Fulfilling Attacks," American Economic Review, 1998, 88, 587-597.

Obstfeld, Maurice, "Models of Currency Crises with Self-Fulfilling Features," European Economic Review, 1996, 40, 1037-1048.

Pathak, Parag and Jean Tirole, "Addendum to 'Pegs, Risk Management, and Financial Crisis'," 2004. Available upon request from authors.

Ranciere, Romain, Aaron Tornell, and Frank Westermann, "Crises and Growth: A Reevaluation," 2003. UCLA, mimeo.

Reinhart, Carmen, Kenneth Rogoff, and Miguel Savastano, "Addicted to Dollars," 2003. NBER Working Paper, w10015.

Schneider, Martin and Aaron Tornell, "Balance Sheet Effects, Bailout Guarantees and Financial Crises," 2003. UCLA, forthcoming, Review of Economic Studies.

Summers, Lawrence H., "International Financial Crises: Causes, Prevention, and Cures," American Economic Review, 2000, 90, 1-16.

Tirole, Jean, "Inefficient Foreign Borrowing: A Dual- and Common-Agency Perspective," American Economic Review, 2003, 93, 1678-1702.

Tornell, Aaron and Andres Velasco, "Fixed versus Flexible Exchange Rates: Which Provides More Discipline?," Journal of Monetary Economics, 2000, 45, 399-436. 